\title{
A missense mutation ( $p$. Tyr452Cys) in the CAD gene compromises reproductive success in French Normande cattle
}

\author{
M. Mesbah-Uddin, ${ }^{1,2 *}$ C. Hoze,${ }^{2,3}$ P. Michot, ${ }^{2,3}$ A. Barbat, ${ }^{2}$ R. Lefebvre, ${ }^{2}$ M. Boussaha, ${ }^{2}$ G. Sahana, ${ }^{1}$ S. Fritz, ${ }^{2,3}$ \\ D. Boichard, ${ }^{2}$ and A. Capitan ${ }^{2,3 *}$ \\ ${ }^{1}$ Department of Molecular Biology and Genetics, Center for Quantitative Genetics and Genomics, Aarhus University, 8830 Tjele, Denmark \\ ${ }^{2} \mathrm{GABI}$, INRA, AgroParisTech, Université Paris-Saclay, 78350 Jouy-en-Josas, France \\ ${ }^{3}$ Allice, 75595 Paris, France
}

\section{ABSTRACT}

We scanned the genome of 77,815 Normande cattle with different Illumina SNP chips (Illumina Inc., San Diego, CA) to map recessive embryonic lethal mutations using homozygous haplotype deficiency. We detected 2 novel haplotypes on chromosomes 11 and 24 but did not confirm 6 previously reported haplotypes. The one on chromosome 11 showed a marked reduction in conception rates and moderate decrease in nonreturn rate in at-risk versus control mating, supporting late embryonic mortality. After fine mapping and analyzing whole-genome sequences, we prioritized a missense mutation in CAD (g.72399397T >C; p.Tyr452Cys) - a gene encoding a protein (carbamoyl-phosphate synthetase 2, aspartate transcarbamylase, and dihydroorotase) essential for de novo pyrimidine biosynthesis - as a candidate causal variant. This transition mutation replaces a tyrosine residue, which is perfectly conserved among living organisms, with a cysteine residue in the carbamoyl-phosphate synthetase 2 domain of the protein. A single animal was confirmed to be homozygous for the mutation based on Sanger sequencing. However, large-scale genotyping of the candidate variant with the Illumina EuroG10k BeadChip revealed an absence of live homozygotes in a panel of 33,323 Normande animals and an absence of carriers in 348,593 animals from 19 other cattle breeds. These results support recessive embryonic lethality with nearly complete penetrance, as was previously reported in $C A D$ mutants in several eukaryote species. The only homozygous cow had extremely poor udder conformation, suggesting a potential role of $C A D$ in udder development, but no effect was detected when comparing daughter yield deviations of 250 heterozygous bulls with that of 2,912 homozygotes

\footnotetext{
Received December 4, 2018.

Accepted March 15, 2019.

*Corresponding authors: mdmesbah@gmail.com and aurelien. capitan@inra.fr
}

for the ancestral allele. Together, our results showed the importance of large-scale screening for homozygous haplotype deficiency with hundreds of thousands of animals, validating results with an independent data set, and considering unexpected live homozygotes, to avoid both false-positive and false-negative discoveries. These discoveries will be used primarily in mating decisions to avoid at-risk mating. In addition, we recommend including $C A D$ in the breeding objectives of Normande cattle.

Key words: embryonic lethal, $C A D$, homozygous haplotype deficiency, dairy cattle, large-scale genotyping

\section{INTRODUCTION}

Inbreeding and genetic drift have increased substantially in dairy cattle over the last decades due to the extensive use of a few elite AI sires (Weigel, 2001; Bjelland et al., 2013). This situation can increase the frequency of some deleterious alleles in the population, and thus unmask recessive genetic defects affecting various fitness traits (Cole et al., 2016).

Homozygosity mapping is an efficient approach to map such recessive deleterious alleles with few inbred live cases (Charlier et al., 2008). However, it requires the prior detection of live animals showing distinctive features, which is not possible for all types of genetic defects (e.g., when homozygotes die very early in the gestation period or when they display symptoms that can be confounded with nongenetic diseases). VanRaden et al. (2011) proposed a new approach for identifying recessive genetic defects from large-scale screening of homozygous haplotype deficiency (HHD). Embryonic lethality or increased perinatal mortality is suspected when homozygotes are significantly less frequently observed than expected based on population frequency. This approach enabled the detection of several haplotypes with both complete and incomplete penetrance in several breeds (Sahana et al., 2013; Pausch et al., 2015; Schwarzenbacher et al., 2016a), though it required tens 
or hundreds of thousands of genotyped individuals for rarer disorders.

However, some of these haplotypes could not be confirmed in independent studies, possibly because of falsepositive results or population structure within a breed. For example, haplotypes HH2 in Holstein and BH1 in Brown Swiss showed significant HHD in the United States (VanRaden et al., 2011) but not in Europe (Fritz et al., 2013; Segelke et al., 2016; Fritz et al., 2018). For this reason, and because no phenotypic association and candidate mutation have been reported so far (McClure et al., 2014), HH2 and BH1 have been recently removed from the list of genetic defects considered by the National Association of Animal Breeders (NAAB) in the United States (Olivier Bulot, World Brown Swiss Federation, Paris, France, personal communication).

Previous studies have highlighted the importance of large-scale genotyping to validate candidate causal mutations (Schwarzenbacher et al., 2016a,b; Michot et al., 2017; Fritz et al., 2018). Our team recently excluded a candidate variant in the $S H B G$ gene for MH1 haplotype in Montbéliarde cattle (Fritz et al., 2013) and validated a new causal variant in the PFAS gene (Michot et al., 2017).

Fritz et al. (2013) reported 6 haplotypes - Normande haplotype (NH) 1 to NH6 - showing significant HHD in 11,466 Normande cattle, including 4 that also showed some reduction in conception rate in at-risk versus control mating. In this large-scale screening, we were interested in validating these haplotypes in Normande cattle, detecting novel loci, and when possible, identifying causal variants.

\section{MATERIALS AND METHODS}

\section{Study Samples and Genotype Data}

We analyzed 77,815 Normande cattle from the French genomic evaluation database genotyped between the year 2008 and 2018 with different Illumina SNP chips (Illumina Inc., San Diego, CA), including the 777K BovineHD BeadChip, 50K BovineSNP50 BeadChip (Matukumalli et al., 2009), BovineLD BeadChip (Boichard et al., 2012a), and EuroG10K BeadChip (Boichard et al., 2018). In the total data set, 27,632 animals had both parents genotyped, and 49,690 had sire and maternal grandsire (MGS) genotyped. The others (353 and 140 animals with no or only a single parent genotyped, respectively) were included as sires or MGS only. Because this data set included all animals studied by Fritz et al. (2013), we also performed a specific analysis on this subpopulation. This data set comprised 2,303 animals with both parents genotyped, and 9,163 animals with sire and MGS (but not dam) genotyped, as well as 111 sires or MGS with no or a single parent genotyped.

Quality control of the genotype data was carried out following the French genomic evaluation pipeline. This included (1) filtering of low-quality genotypes, (2) verifying the pedigree for Mendelian inconsistency, and (3) phasing and imputing genotypes (Sargolzaei et al., 2014) from low to medium density (for details, see Boichard et al., 2012b). After quality control, 43,801 autosomal SNP from the BovineSNP50 BeadChip were kept for subsequent analysis. The genomic coordinates presented in this study refer to bovine genome assembly UMD3.1 (Zimin et al., 2009).

\section{Screening for HHD}

Following the method used by VanRaden et al. (2011) and Fritz et al. (2013), we screened the 29 bovine autosomes, with sliding windows of 20 consecutive markers, for HHD. We counted occurrences of every haplotype and calculated population frequency from the maternal chromosomal phases. In addition, we estimated the expected number of homozygotes using within-family transmission probability, such as from carrier sires and dams to offspring or from carrier sires and MGS (with ungenotyped dam) to offspring. For subsequent analyses, we considered haplotypes with population frequency greater than $1.0 \%$, representing on average 17 different haplotypes for each 20-marker window (range 4 to 34 haplotypes). In total, we performed 717,747 tests to identify HHD, and therefore considered haplotypes with $P<1.39 \times 10^{-8}$ for further analysis, after correcting for multiple testing at $1 \%$ level of significance. The expected number of homozygotes (lambda) assuming neutrality was computed from sire, dam, or MGS genotypes and frequency in the population as in Fritz et al. (2013). We calculated the probability of observing $q$ homozygotes with expectation of lambda, using the Poisson distribution "ppois $(q$, lambda)" function in R software (version 3.4.3; R Core Team, 2017). After multiple testing correction, we considered haplotypes for further analysis when the ratio of observed to expected homozygotes was less than 0.25 .

\section{Comparison of Haplotype Status for NH1 to NH6 in 2013 and Present Studies}

Haplotype status as computed by Fritz et al. (2013) was available for 2,364 AI bulls out of the 11,466 animals initially studied. We compared carrier status between the 2 studies for these animals. 


\section{Analysis of the Survival of Animals Homozygous for $\mathrm{NH} 2$}

Information on the date of birth, date of death and cause (slaughter or natural death) was extracted from the French genomic evaluation database for 228 females homozygous for $\mathrm{NH} 2$ and 8,871 nonhomozygous paternal half-sisters. In both groups, we evaluated the proportion of animals that died of natural causes at 1 , 2 , and 3 yr of age.

\section{Evaluation of Haplotype Effect on Fertility Traits}

We evaluated the haplotype effect on 2 "binary" female fertility traits, conception rate $(\mathbf{C R})$ and nonreturn rate at $56 \mathrm{~d}$ (NRR56), separately in heifers and lactating cows, using phenotypic records from the French genomic evaluation database (period January 2000 to May 2018). The CR was defined as a measure of success (1) or failure (0) of each insemination, assessed by a calving after a compatible gestation length; NRR56 measures whether a female is reinseminated within $56 \mathrm{~d}$ after a previous insemination. It was coded 0 if at least one insemination is recorded within this period and 1 otherwise. As both phenotypes are routinely evaluated in the French national evaluation system, nongenetic effect estimates (e.g., effects of herd $\times$ year, year $\times$ month of insemination, parity, DIM, AI technician, use of sexed semen) were available and used to preadjust the phenotypes of these 2 traits. The mating class was coded 1 for at-risk mating (between carrier bulls and daughters of carrier bulls), and 0 for nonrisk mating (all other combinations of genotypes regarding the bulls and the sires of the dams). We analyzed the phenotypic effect of the haplotype between at-risk mating and nonrisk mating using the following fixed-effect model:

$$
Y_{i j k}=\mu+\text { sire }_{j}+\text { mating- } \text { class }_{k}+e_{i j k},
$$

where $Y_{i j k}$ represents the phenotype of interest (i.e., adjusted CR or NRR56), $\mu$ is the overall phenotypic mean, sire $_{j}$ is the fixed sire effect, mating-class $k$ is the fixed effect of the mating status, and $e_{i j k}$ is the random residual error. The analysis was performed using the GLM procedure of SAS software (version 9.4; SAS Institute Inc., Cary, NC). In addition, we calculated the expected decrease in fertility, assuming full lethality under homozygosity, using the formula

$$
\frac{1}{4}\left(\frac{1}{2-f_{\text {hap_k }}}\right) \mu,
$$

where $f_{\text {hap } \_k}$ is the frequency of haplotype $e_{k}$, and $\mu$ is the phenotypic mean for CR or NRR56 (as in Michot et al., 2017).

\section{Fine Mapping the NH7 Locus}

To fine map the causal mutation associated with the newly detected NH7 haplotype, we followed the approach used by Sonstegard et al. (2013) and Fritz et al. (2018). Briefly, this consisted in identifying phenotypically normal animals presenting a run-of-homozygosity (ROH) on either side of the candidate haplotype among the inbred descendant of the bull (Nonnic; NORFRAM002977029292), the most ancient and influential carrier of NH7 in our data set. Such asymptomatic individuals are very unlikely to be homozygous for the causal mutation; thus, regions with long $\mathrm{ROH}$ can be ruled out for causal variant screening.

\section{Analyzing Whole-Genome Sequence Data for Candidate Mutations}

We analyzed the whole-genome sequence (WGS) of 2,333 animals (44 Normande cattle and 2,289 animals from other cattle breeds) from the 1000 Bull Genomes Project (Run6, 1KBGP; Daetwyler et al., 2014) to identify putative causal variants. Among the WGS animals, only 2 Normande bulls carried NH7 and the rest did not. We performed Pearson correlation between haplotype status and allele dosage for all biallelic SNPs and small insertions and deletions (indels) within NH7 $( \pm 500 \mathrm{~kb})$, to identify highly associated variants. Both haplotype status and allele dosage were coded as 0,1 , or 2 when the animal carried either 0,1 , or 2 copies of alternative allele/candidate haplotype, respectively. We presented squared values of Pearson correlations $\left(\mathrm{r}^{2}\right)$ in a scatterplot.

We also analyzed structural variant $(\mathbf{S V})$ calls on 389 whole-genome sequenced French cattle, which included 44 WGS Normande cattle and 345 animals from other breeds. The SV were identified using 3 softwares, BreakDancer v1.3.6 (Chen et al., 2009), Delly v0.6.1 (Rausch et al., 2012), and Pindel v2.5 (Ye et al., 2009), and consensus SV calls from these tools were included for the analysis (for details see Letaief et al., 2017). For candidate SV, we focused our search within NH7 and $\pm 500 \mathrm{~kb}$ surrounding regions. We checked for concordance between carrier status of NH7 and SV.

\section{Integrative Annotation of Candidate Mutations and Nearby Genes}

We annotated all strongly correlated variants (r $>0.8$ ) using Variant Effect Predictor (VEP v87) soft- 
ware (McLaren et al., 2016), which includes annotation of sequence ontology, SIFT score (Kumar et al., 2009) for missense variants, overlapping gene name, and so on. We retrieved 3 gene-level constraint scores: (1) the ratio of nonsynonymous $\left(d_{N}\right)$ to synonymous $\left(d_{S}\right)$ substitution rate $\left(\boldsymbol{d}_{N} / \boldsymbol{d}_{S}\right.$ scores $)$ for cow-human 1-to-1 orthologs, using BioMart (Kinsella et al., 2011; Zerbino et al., 2018); (2) residual variation intolerance score (RVIS) (Petrovski et al., 2013); and (3) missense Z-scores (Lek et al., 2016) for human orthologs of cattle genes. We converted genomic coordinates of variants from UMD3.1/bosTau6 to GRCh37/hg19 to retrieve variant-level conservation scores using LiftOver software (http://genome.ucsc.edu/cgi-bin/hgLiftOver; Casper et al., 2018). We retrieved evolutionary conservation statistics, such as Genomic Evolutionary Rate Profiling (GERP ++ ) "rejected substitutions" scores for 35 mammalian alignments (Davydov et al., 2010) and PhyloP and PhastCons scores for 100-vertebrate alignments (Pollard et al., 2010), using UCSC Table Browser (http://genome.ucsc.edu/cgi-bin/hgTables; Karolchik et al., 2004).

\section{Multiple-Sequence Alignment}

We performed multiple-sequence alignment among 24 different species, representing 6 groups: vertebrates, metazoan, plants, fungi, protists, and bacteria. We extracted protein sequences from either Ensembl Genomes (Kersey et al., 2018) or UniProt (UniProt, 2017). We used Clustal Omega version-1.2.4 (Sievers et al., 2011) for multiple-sequence alignment. For the candidate gene, we also retrieved functional annotation of protein domains from NCBI's Conserved Domain Database (CDD, https://www.ncbi.nlm.nih.gov/cdd; Marchler-Bauer et al., 2017).

\section{Large-Scale Genotyping of the CAD Candidate Mutation in French Cattle Breeds}

A molecular test was designed to genotype a candidate missense mutation in the $C A D$ gene (g.72399397A $>\mathrm{G}$ on chromosome 11, CAD p.Tyr452Cys) with the EuroG10K BeadChip (Boichard et al., 2018) routinely used for genomic evaluation. Genotypes of 381,916 animals from 20 French cattle breeds were available for this variant.

\section{Genotyping of the CAD Mutation by PCR and Sanger Sequencing}

We used PCR and Sanger sequencing to genotype the same mutation in a single individual found to be homozygous for the NH7 haplotype based on $50 \mathrm{~K}$ genotypes, and a noncarrier animal. DNA was obtained from Labogena DNA (Jouy-en-Josas, France). We designed primers using Primer3 software (Untergasser et al., 2012). The forward and reverse primers were 5'-AGGGGATCACAGAATTGGCA- $3^{\prime}$ and 5'-GCCTCTGTCTCCTTGGGATT-3', respectively. We performed PCR using GoTaq Flexi DNA Polymerase (Promega, Madison, WI) in the Mastercycler Pro thermocycler (Eppendorf, Montesson, France), following the manufacturer's instructions, and sent amplicons to Eurofins MWG (Hilden, Germany) for sequencing. We used novoSNP software (Weckx et al., 2005) for variant calling and visualization.

\section{Phenotypic Examination of the Homozygous Cow and Paternal Half-Sisters}

Clinical examination of the NH7 homozygote cow, named "Genetique," was not possible because this animal was slaughtered at the beginning of her first lactation due to poor udder conformation (personal communication from the breeder). However, performance records for 34 morphological traits were available for this cow and its 2,239 paternal half-sisters from the French National databases (see Supplemental Figure S1; https: //doi.org/10.3168/jds.2018-16100). Individual performances were ranked for each trait and the position of Genetique was expressed in term of percentiles.

\section{Effect of the CAD Mutation on Udder Conformation Traits}

Because Genetique displayed extremely poor udder conformation, we evaluated the effect of the $C A D$ missense mutation on 4 udder traits: teat direction (TD), teat placement (TP), udder cleft (UC), and udder depth (UD). These traits are initially recorded in a scale of 1 (low) to 9 (high) (see ICAR, 2018, for details), before being adjusted for nongenetic factors and mean-centered in the French national evaluation system. Daughter yield deviations were available for 250 heterozygous carriers and 2,912 noncarriers of the $C A D$ mutation. The phenotypic effect of the mutation was estimated using the following fixed effect model:

$$
Y_{i j k}=\mu+\text { sire }_{j}+C A D \_ \text {genotype } e_{k}+e_{i j k},
$$

where $Y_{i j k}$ represents the phenotype of interest (i.e., daughter yield deviationsfor TD, TP, UC, or UD), $\mu$ is the overall phenotypic mean, sire $_{j}$ is the fixed effect of the sire of the bull, $C A D_{-}$genotype $_{k}$ is the fixed effect 
Table 1. List of Normande haplotypes with deficit of homozygotes (haplotypes NH1 to NH6 from Fritz et al., 2013 ; NH7 and NH8 from the present study)

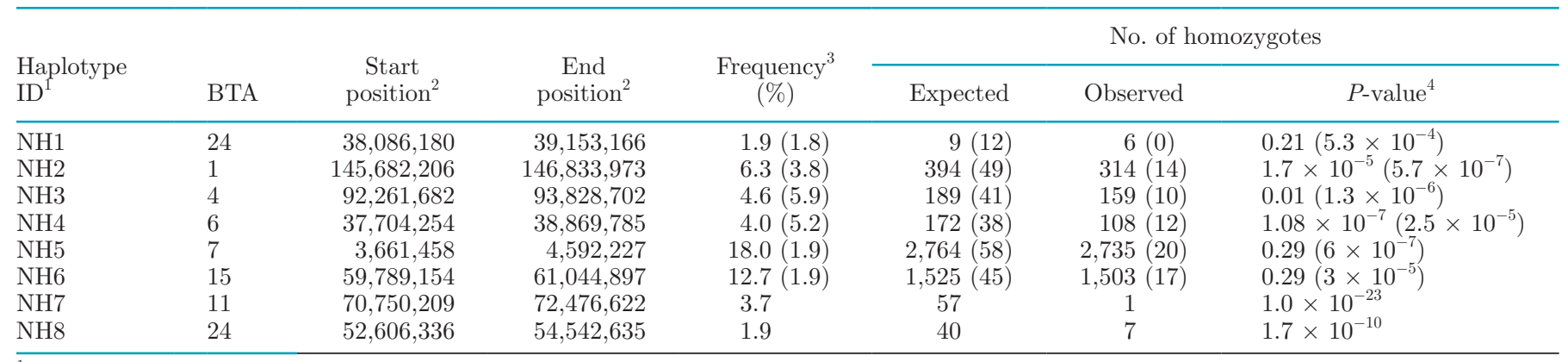

${ }^{1}$ Genotypes for markers ARS-BFGL-NGS-97976 and BTA-58084-no-rs within NH1, Hapmap59512-rs29027076 within NH3, BTB-01218649 within NH5, and BTA-37438-no-rs and ARS-BFGL-NGS-29141 within NH6 haplotype were considered in Fritz et al. (2013) but not in the present study.

${ }^{2}$ Start and end positions represent first and last 50K marker of the haplotype; positions correspond to bovine genome assembly UMD3.1 (Zimin et al., 2009).

${ }^{3}$ Information within parentheses and Normande haplotype NH1 to NH6 are from Fritz et al. (2013).

${ }^{4} P$-values are from Poisson distribution, calculated using R software's "ppois( $q=$ observed, lambda $=$ expected)" function (R Core Team, 2017).

of the genotype ( $k=A G$ or $A A$ ), and $e_{i j k}$ is the random residual error. The analysis was performed using the GLM procedure of SAS software (SAS Institute Inc.).

\section{RESULTS AND DISCUSSION}

\section{HHD in Normande Cattle}

In a sliding window approach, we analyzed 77,815 Normande cattle phased and imputed for 43,801 autosomal markers, to identify HHD. Surprisingly, none of the 6 Normande haplotypes (NH1 to NH6) previously reported by Fritz et al. (2013) showed significant HHD in this follow-up study after correction for multiple testing (Table 1).

To elucidate the causes of these discrepancies, we reanalyzed the mapping population of 11,466 Normande cattle from Fritz et al. (2013) using the current French phasing and imputation data set. In contrast to Fritz et al. (2013), the current data set did not include markers of the Illumina BovineSNP50v1 BeadChip, which have been removed from the subsequent versions of the chip for technical reasons. This change concerns markers ARS-BFGL-NGS-97976 and BTA-58084-no-rs within NH1; Hapmap59512-rs29027076 within NH3, BTB-01218649 within NH5; and BTA-37438-no-rs and ARS-BFGL-NGS-29141 within the NH6 haplotype. The removal of these problematic markers, which likely caused local phasing and imputation errors, explains the substantial changes in haplotype frequencies (Table 1) and carrier status (Supplemental Table S1; https:// doi.org/10.3168/jds.2018-16100) observed between the 2 studies. Insufficient correction for multiple testing (arbitrary threshold of $P<1 \times 10^{-4}$ instead of Bonferroni correction) was another reason for the false discovery. Among the 6 haplotypes, only NH2 was significant for HHD after Bonferroni correction (Supplemental Table S2; https://doi.org/10.3168/jds.2018-16100).

It is worth mentioning that the population analyzed by Fritz et al. (2013) consisted of animals 1 yr or older, whereas the present data set included numerous young animals genotyped in their first months of life, which is expected to reduce the power of detection when mapping loci responsible for juvenile mortality. To verify whether NH2 is associated with postnatal mortality, and perhaps explain why it was not detected in the present study, we analyzed the survival of 228 homozygous females and 8,871 nonhomozygous paternal halfsisters. We found no difference between the 2 groups at 1, 2, and 3 yr of age (Supplemental Table S3; https:/ /doi.org/10.3168/jds.2018-16100). In this context, we assume that $\mathrm{NH} 2$ was a false positive because of the lower power of detection in the analysis of Fritz et al. (2013) compared with that of the current study. Indeed, the present data set is 7-fold larger than the previous one, and the frequency of NH2 more than doubled in the population, which increased the probability of observing homozygotes.

Importantly, we detected 2 novel haplotypes with significant deficit of homozygotes $\left(P<1.39 \times 10^{-8}\right)$. One, $\mathrm{NH} 7$, was located on chromosome 11 between positions $70,750,209$ and $72,476,622 \mathrm{bp}$, and the other, NH8, on chromosome 24 between positions 52,606,336 and $54,542,635 \mathrm{bp}$. Haplotype frequencies in the Normande breed were 3.7 and $1.9 \%$ for $\mathrm{NH} 7$ and NH8, respectively. In our data set, we observed 1 homozygote for NH7 and 7 homozygotes for NH8, whereas the expectations under neutrality were 57 and 40, respectively (Table 1 ). 
Table 2. Estimated effect of Normande haplotypes NH7 and NH8 on conception rate (CR) and nonreturn rate at 56 d (NRR56) in at-risk mating $^{1}$

\begin{tabular}{|c|c|c|c|c|c|c|c|c|}
\hline Haplotype & Trait & Category & \multicolumn{3}{|c|}{ Number of matings } & $\begin{array}{c}\text { Mean } \\
(\%)\end{array}$ & \multicolumn{2}{|c|}{ Effect on fertility (\%) } \\
\hline \multirow[t]{3}{*}{ NH7 } & CR & Heifer & $2,981,552$ & 14,474 & $2,996,026$ & 57.37 & -7.30 & -5.53 \\
\hline & NRR56 & Heifer & $1,870,062$ & 7,513 & $1,877,575$ & 76.62 & -9.75 & -1.76 \\
\hline & & Cow & $3,999,038$ & 22,494 & $4,021,532$ & 67.13 & -8.55 & -1.52 \\
\hline \multirow[t]{2}{*}{ NH8 } & $\mathrm{CR}$ & Heifer & $3,014,200$ & 2,497 & $3,016,697$ & 57.44 & -7.25 & 0.64 \\
\hline & & Cow & $4,047,881$ & 2,261 & $4,050,142$ & 67.16 & -8.47 & 0.55 \\
\hline
\end{tabular}

${ }^{1}$ At-risk matings are defined by mating between a carrier AI bull and a daughter of a carrier sire. Nonrisk mating includes all other combinations (carrier $\times$ noncarrier, noncarrier $\times$ carrier, and noncarrier $\times$ noncarrier $)$.

${ }^{2}$ Expected effects on CR and NRR56 were calculated using the formula $\frac{1}{4}\left(\frac{1}{2-f_{\text {hap }} k}\right) \mu$, where $f_{\text {hap } \_k}$ is the frequency of haplotype $k$ (NH7 or NH8)
in the population, and $\mu$ is the phenotypic mean of CR or NRR56.

The oldest carriers in our data set were born in 1977 for NH7 [Newgate; NORFRAM002277007498 and Nonnic; NORFRAM002977029292, 2 sons of Valhalla (NORFRAM007668031767) who was not genotyped] and in 2003 for NH8 (Uvray; NORFRAM002951401444). Because NH8 is a relatively new haplotype in Normande cattle, created by a recombination in the maternal gamete that was transmitted to Uvray, there are fewer opportunities for it to be observed in the homozygous state in the population. However, we considered both haplotypes for analyzing their effect on CR and NRR56.

\section{Haplotype NH7 but not NH8 Compromises Conception Rate in Normande Cattle}

To elucidate whether $\mathrm{NH} 7$ and $\mathrm{NH} 8$ have negative effect on CR and NRR56, we analyzed $\sim 10$ million and $\sim 6$ million mating records, respectively, between genotyped bulls and daughters of genotyped bulls (Table 2).

For NH7, we observed a marked decrease in CR of $5.53 \%$ in heifers and $5.56 \%$ in cows, which is close to the expectation (7.30 and $6.01 \%$, respectively). We also observed a moderate decrease in NRR56 of $1.76 \%$ in heifers and $1.52 \%$ in cows, much lower than the 9.75 and $8.55 \%$ expected values in both groups, assuming complete lethality in homozygotes. Reinsemination within $56 \mathrm{~d}$ (NRR56) is an indirect measure of embryonic losses within $35 \mathrm{~d}$ of gestation, because the average estrous cycle in cow is $21 \mathrm{~d}$ (Reece et al., 2015). Our analysis shows that, on average, only $18 \%$ of the expected embryonic losses occurred within $35 \mathrm{~d}$ of gestation, whereas the majority of the failure may occur later in the gestation. Here, we suspect that gradual embryonic loss occurred over the length of gestation, rather than abrupt mass loss in the first month after fertilization.
We also analyzed the effect of NH8 on CR and NRR56, and found that this haplotype does not affect these 2 traits in Normande cattle (Table 2). It is worth noting that the power of detection was limited by the reduced number of at-risk matings $(0.06 \%$ vs. $>0.5 \%$ of total mating for NH7) in our data set because of the low frequency $(1.9 \%)$ and the recent spreading of this haplotype in the population. Another possibility is that NH8 caused postnatal mortality, possibly with incomplete penetrance. Seven homozygotes, all inbred descendants of Uvray, have been observed for this haplotype. These were all alive and aged between $11 \mathrm{mo}$ and $3 \mathrm{yr}$ at the time of this study. Despite NH8's significant HHD, it is necessary to accumulate more carrier-to-carrier mating, and inheritance in more generations, to be confident about the effect and HHD. Considering this and the fact that juvenile mortality was outside the scope of our study, we focused the subsequent analyses on NH7.

\section{Homozygote for NH7 Has Particularly Poor Udder Morphology}

We found a single cow, Genetique, homozygous for NH7 haplotype and for a $20-\mathrm{Mb}$ surrounding segment $(\sim 4.2 \mathrm{Mb}$ upstream and $14.8 \mathrm{Mb}$ downstream of the source haplotype) due to recent inbreeding. This individual deserves special attention. If it is homozygous at the causal mutation, penetrance is not complete but the animal may be affected by severe abnormality. Alternatively, it could be homozygous for the haplotype but not for the mutation, by carrying an ancestral version of the haplotype before the mutation event occurred along with the lethal haplotype. The breeder informed us that this animal had normal health but was slaughtered during its first lactation because of very poor udder morphology. To verify this, we analyzed performance 


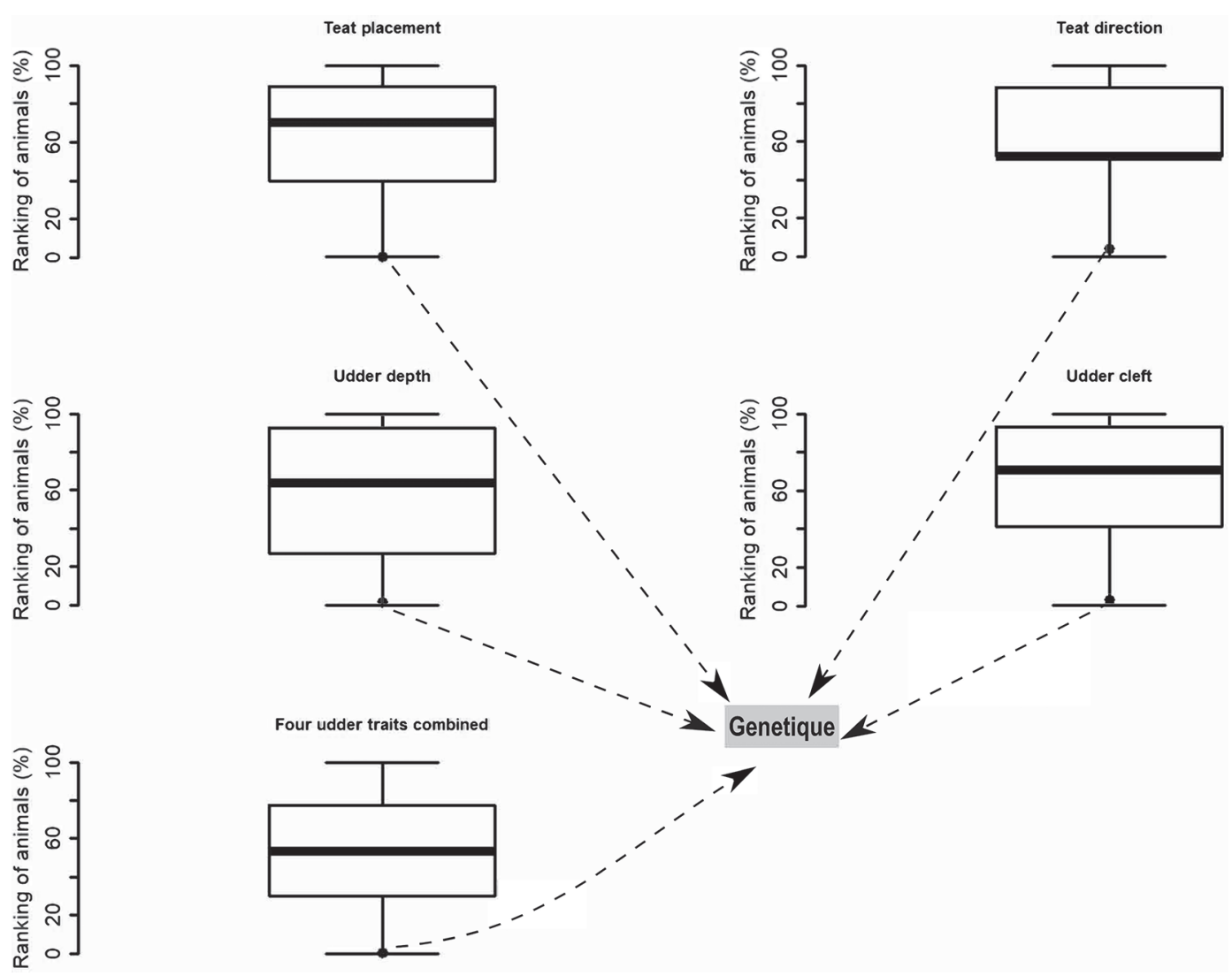

Figure 1. Ranking of animals $(\mathrm{n}=2,240)$ for 4 udder traits (\%). Black dots indicate the relative percentile of Genetique (the cow homozygous for Normande haplotype NH7) among the 2,239 paternal half-sisters. The percentile was calculated as follows: [no. of animals with ( $\leq$ ) a given score/total animals] $\times 100$. Combined scores (per animal): summation of scores for 4 udder traits, followed by calculation of relative percentile for the given animal. The boxplots were drawn using R software's "boxplot" function (R Core Team, 2017). Here, the box represents the interquartile range (middle $50 \%$ of the data set); the solid line represents the median value; and the lower and upper whiskers extend to 5 th and 95 th percentiles, respectively.

records for 34 morphological traits on Genetique and its 2,239 paternal half-sisters. We confirmed that traits were in the normal range, except for 4 udder traits; that is, teat placement, teat direction, udder depth, and udder cleft, for which it ranked among the lowest 1 , 5,2 , and $4 \%$ of its siblings, respectively (Figure 1 and Supplemental Figure S1; https://doi.org/10.3168/jds .2018-16100). Furthermore, Genetique ranked among the lowest $1 \%$ on a linear combination of the scores of the 4 traits (Figure 1).

\section{Fine Mapping of the NH7 Locus in a 1.01-Mb Genomic Region}

To fine-map the NH7 locus, we analyzed the pedigree and found that among genotyped animals, half-brothers Newgate (NORFRAM002277007498) and Nonnic (NORFRAM002977029292) were the 2 most ancient carriers of the haplotype. Of these, however, Nonnic is the ancestor of many bulls with high breeding value. For example, Elixir (NORFRAM 005389014161), a descendent of Nonnic, is the sixth most influential bull in the Normande breed with $4.7 \%$ contribution in the population (IDELE, 2017). Therefore, we considered only phenotypically normal descendants of Nonnic (and Elixir) to fine-map the NH7 locus.

We identified 2 cows, 0520 (NORFRAF003708210520) and Fanion (NORFRAF001447822444), presenting an $\mathrm{ROH}$ on either side of the candidate haplotype (Figure 2). Both inherited NH7 paternally from Nonnic (through Elixir) and NH7 recombinant haplotypes maternally. In dairy cattle, females were rarely genotyped and therefore, it is difficult to track maternally inherited recombinant haplotypes (Adams et al., 2016). Nevertheless, it is likely, from pedigree and sire-haplotype analyses, that Nimbus (Figure 2a) received the recombinant haplotype from Elixir and passed it to 0520. On the other hand, Fanion received a portion of 
(a)

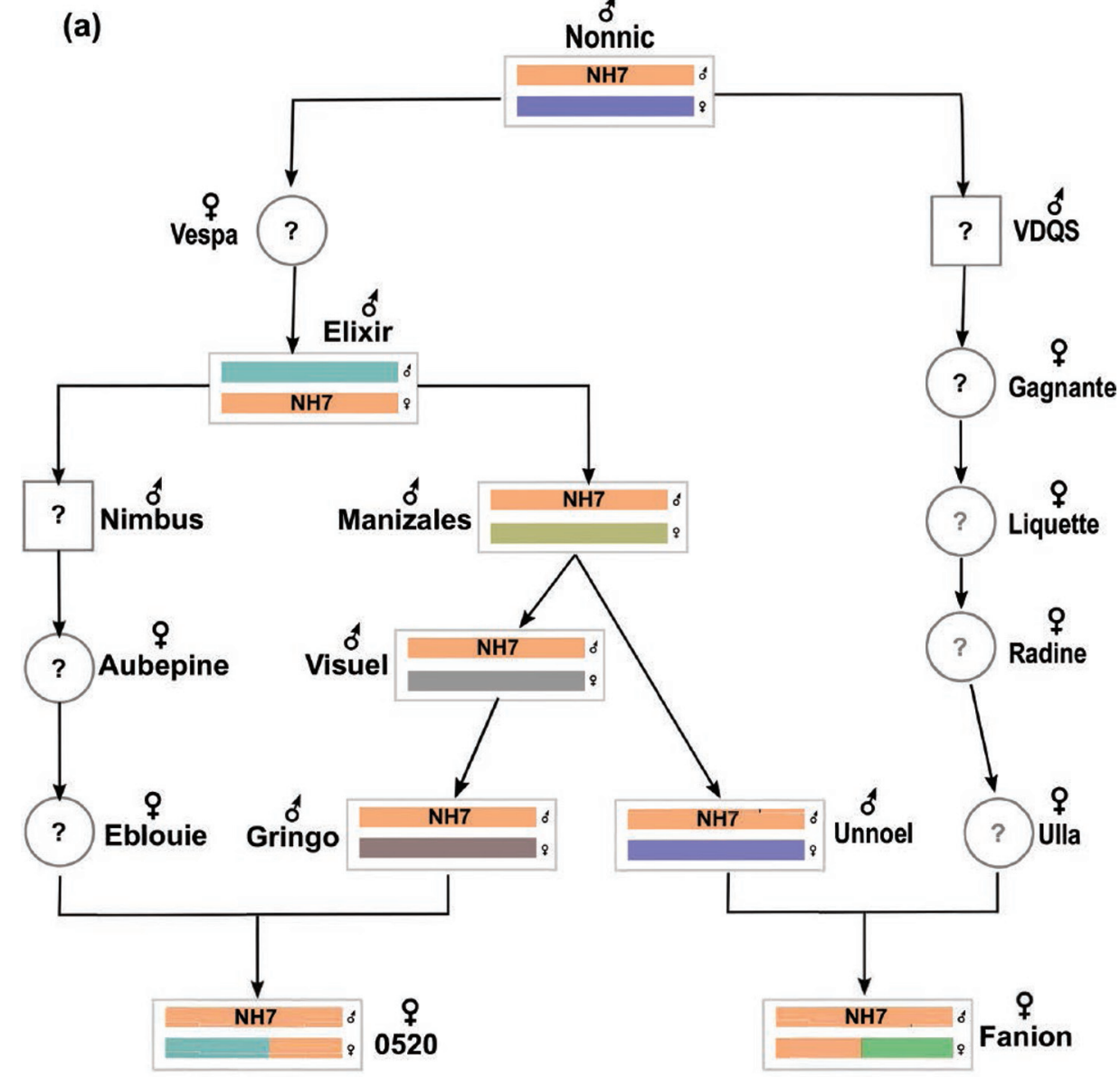

(b)

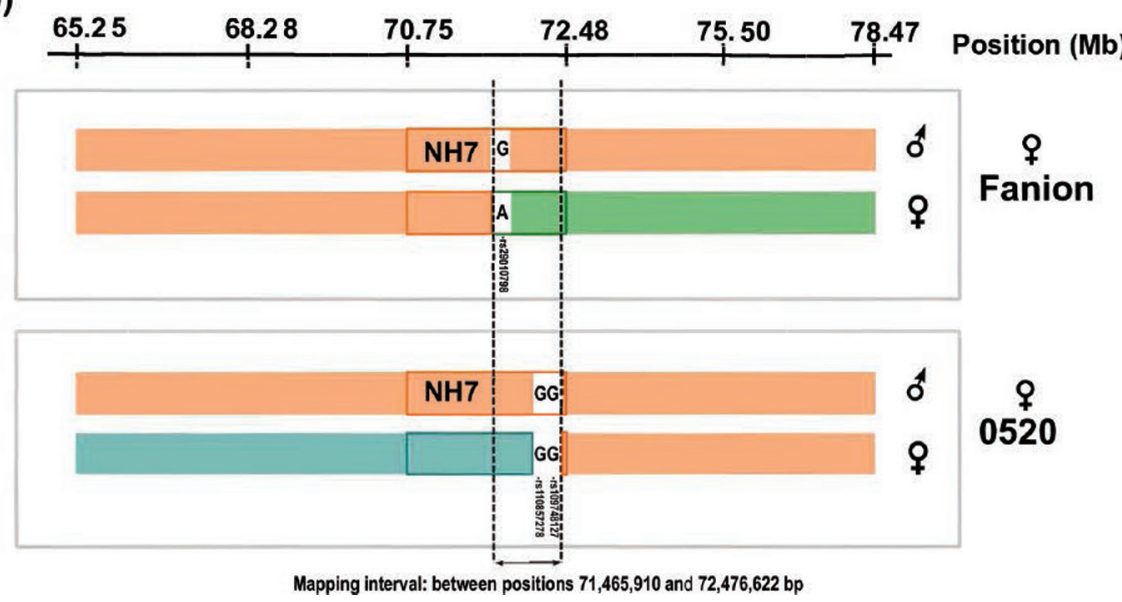

Figure 2. Fine mapping at the Normande haplotype NH7 locus. (a) Pedigrees of the 2 inbred descendants of Nonnic (NORFRAM002977029292): 0520 (NORFRAF003708210520) and Fanion (NORFRAF001447822444); both carry a copy of the 26-marker-long original NH7 haplotype and a recombinant NH7 haplotype, facilitating fine-mapping at the locus (? denotes an ungenotyped animal). (b) Diagram showing original NH7 and recombinant haplotype located between the marker rs41610536 (Chr11:70,750,209) and rs109299742 (Chr11:72,476,622), along with 100 markers on both sides of the haplotype: upstream markers are from rs41569373 (Chr11:65,246.700) to rs41572406 (Chr11:70,703.633), and downstream markers are from rs109666167 (Chr11:72,524,223) to rs110443631 (Chr11:78,468,627). The recombination occurred between marker rs29022293 (Chr11:71,465,910) and rs29010798 (Chr11:71,520,448) in Fanion, and between marker rs110176879 (Chr11:72,159,929) and rs109299742 (Chr11: $72,476,622)$ in 0520 . The resulting critical region is located between marker rs29022293 and rs109299742; that is, in a chromosomal interval between $71,465,910$ and $72,476,622 \mathrm{bp}$. 
the recombinant haplotype from Nonnic, although the origin and source of the remaining portion is inconclusive due to ungenotyped female ancestors (Figure 2a).

It is noteworthy that both cows had normal health and udder morphology. In addition, during this study, 0520 and Fanion were in their second and fourth lactations, respectively. Such phenotypically normal animals are very unlikely to be homozygous for the genomic region harboring the causal mutation, unless the mutation is not fully penetrant. Under this assumption, the critical interval is defined by the 2 recombination points located (1) between marker rs29022293 (Chr11: $71,465,910)$ and rs29010798 (Chr11:71,520,448) in Fanion, and (2) between marker rs110176879 (Chr11:72 ,159,929) and rs109299742 (Chr11:72,476,622), in 0520. This enabled us to fine-map the locus from a $\sim 1.73-\mathrm{Mb}$ initial region to a $\sim 1.01-\mathrm{Mb}$ mutation-critical region (Figure 2b).

\section{Identification of Causal Variant from WGS Data}

To identify putative causal variants, we considered biallelic WGS variants (SNP and indels) and large SV. We used SV calls on 389 WGS French cattle (2
NH7 carriers and 387 noncarriers) to identify SV that overlapped the NH7 haplotype and the $\pm 500 \mathrm{~kb}$ surrounding regions. We identified 2 deletions and 1 inversion within this interval, but none was present in the genomes of the NH7 carriers (Supplemental Table S4; https://doi.org/10.3168/jds.2018-16100).

Then, we determined Pearson correlations between NH7 carrier status of 2,333 animals from the 1KBGP (2 carriers and 2,331 noncarriers) and allele dosages for 33,640 biallelic WGS variants within the haplotype $( \pm 500 \mathrm{~kb})$. Here, we identified 8 strongly correlated (Pearson correlation, $\mathrm{r}>0.8$ ) variants within the given interval (Figure 3). All these variants had high confidence call (average phred-scaled quality $=162$; minimum $=97$ ), with sufficient mapping quality (average $=57 ;$ minimum $=33$ ) and read coverage (average $=$ $11.75 \times ;$ minimum $=8.95 \times)$. Interestingly, 5 out of the 8 variants were within our fine-mapped critical region, which could include the causal variant. However, it is known from studies that the best candidates do not always have perfect correlation with the causal haplotype (Michot et al., 2017; Fritz et al., 2018), which could be due to various artifacts (e.g., errors in phasing and imputation, errors in sequencing and WGS genotype calls,

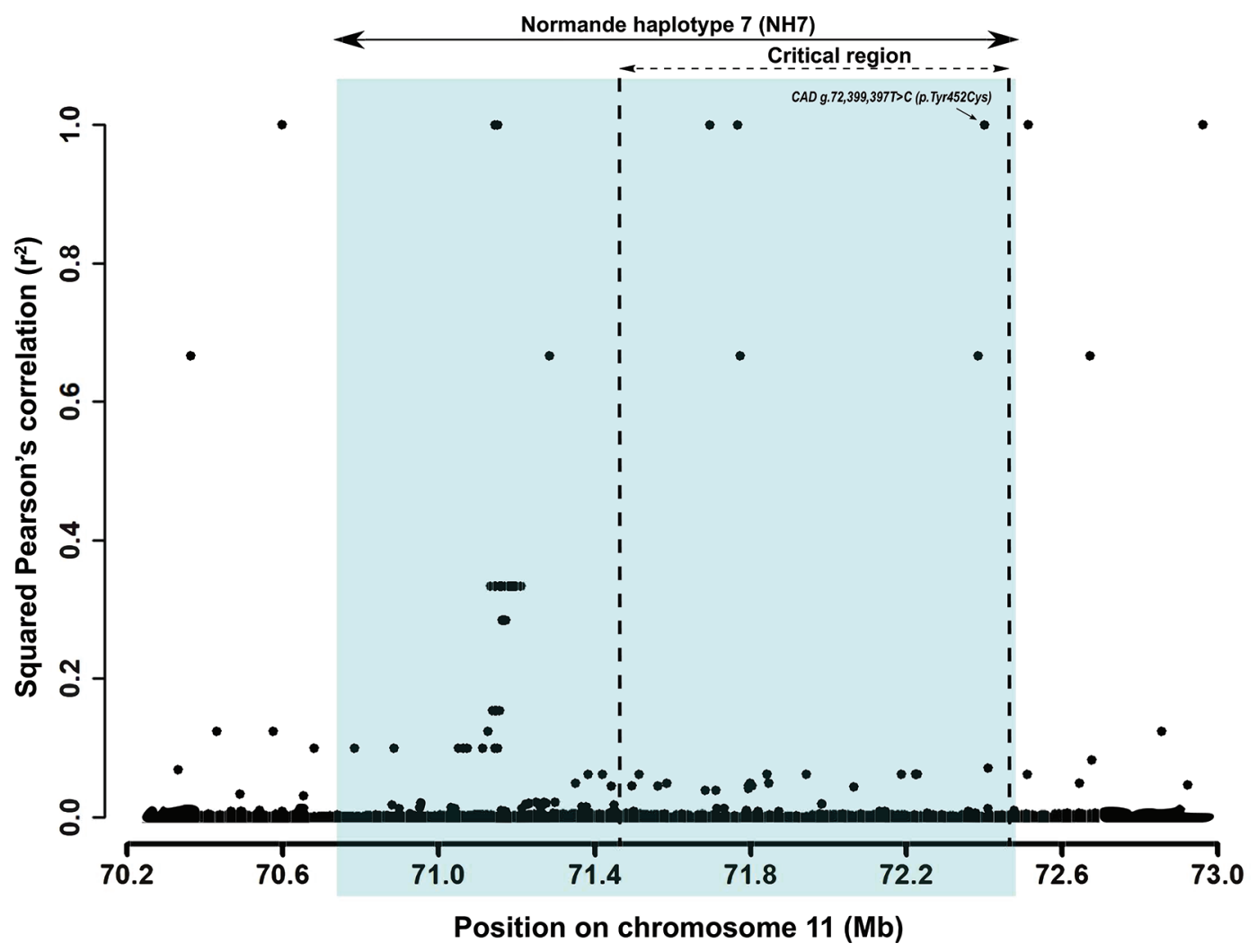

Figure 3. Identification of putative causal variants within the Normande haplotype NH7 locus ( $\pm 500 \mathrm{~kb})$ using Pearson correlation between haplotype status and allele dosage of whole-genome sequencing (WGS) variants. Each dot in the scatterplot indicates a WGS variant. The perfectly correlated $\left(\mathrm{r}^{2}=1\right) C A D$ missense mutation is indicated by an arrow (with annotation). 
incomplete linkage disequilibrium with causal variant). We therefore considered all 8 variants for subsequent gene- and variant-level prioritization.

We annotated these 8 WGS variants using the VEP software tool (version 87) from Ensembl (McLaren et al., 2016), including 1 intergenic variant, 2 intronic variants in $P L B 1,3$ intronic variants in $B R E$, and 1 intronic and 1 missense variants in the $C A D$ gene (Table 3). Next, to prioritize the causal variant from the list, we assessed the functional impact of these variants using 3 gene-level (e.g., $d_{N} / d_{S}$, RVIS, and $Z$-score) and 4 variant-level (e.g., SIFT, GERP, PhyloP, and PhastCons) conservation scores.

To identify selective constraint on genes, we first analyzed the $d_{N} / d_{S}$ ratio of cow-human 1-to-1 orthologs. Although all 3 genes were somewhat constrained $\left(d_{N} /\right.$ $\left.d_{S}<1\right)$, the selective constraint was stronger on $C A D$ and $B R E\left(d_{N} / d_{S}<0.1\right)$. We later focused on RVIS and $Z$-score for human homologs of those genes, and found that $C A D$ was the most constrained gene among the 3 , in terms of tolerance to functional variants (Table 3 ).

We next focused on variant-level conservation scores (SIFT, GERP, PhyloP, and PhastCons) to elucidate the strength of evolutionary constraint on those positions. The SIFT score represents conservation at the protein level and predicts whether an amino acid substitution is deleterious (SIFT $<0.05$ ) or tolerated (SIFT $>0.05$ ) for protein function; SIFT predicted the missense mutation $C A D$ g.72399397T >C (p.Tyr452Cys) to be deleterious for protein function (Table 3). In contrast, GERP, PhyloP, and PhastCons represent conservation at the nucleotide level, generated from multi-species WGS alignments, where higher positive scores indicate stronger evolutionary constraint. We were able to retrieve conservation scores for 7 positions, using LiftOver and UCSC Table Browser, whereas the remaining one did not have any corresponding position from UMD3.1/ bosTau6 to GRCh37/hg19. Interestingly, all 3 classifiers predicted $C A D$ g.72399397T $>\mathrm{C}$ to be the most constrained position, where damaging mutations are purged from the population by strong purifying selection (Table 3).

Integrating gene- and variant-level conservation scores is an effective approach to prioritize causal variants from human genomes (Petrovski et al., 2013). Although bovine genome annotations are somewhat limited to sequence ontology and SIFT scores, incorporating cross-species annotations from well-studied genes or sequence homologs in humans improved our prioritization of the causal variant. Finally, the perfect correlation with NH7, localization within the critical interval, along with strong gene- and variant-level evolutionary conservation, taken together, strongly support $C A D$ g.72399397T $>$ C (p.Tyr452Cys) as the causal variant tagging the (nearly) lethal haplotype in Normande cattle.

\section{Tyrosine Residue at CAD p.Tyr452Cys Is Fully Conserved from Humans to Bacteria}

Pyrimidines are important building blocks of DNA and RNA, as well as precursors for uridine-diphosphate (UDP) sugars that play a vital role in posttranslational modification, such as UDP-dependent glycosylation of proteins (Jones, 1980; Fairbanks et al., 1995). Pyrimidines can be synthesized either de novo from small precursors (e.g., glutamine, ATP, and $\mathrm{HCO}_{3}{ }^{-}$), such as in S-phase of proliferating cells (Mitchell and Hoogenraad, 1975), or by salvaging nucleosides (e.g., uridine) in resting or matured cells (Jones, 1980; Fairbanks et al., 1995). In mammals, the first 3 reactions in the de novo biosynthesis of pyrimidine are catalyzed by $C A D$ - a trifunctional cytosolic protein composed of carbamoylphosphate synthetase 2 (CPSase-2), aspartate transcarbamylase (ATCase), and dihydroorotase (DHOase) domains (Jones, 1980; Moreno-Morcillo et al., 2017). An illustration of bovine $C A D$ protein domains, from NCBI's Conserved Domain Database (CDD), is presented in Figure 4a.

Our candidate $C A D$ mutation is located in the CPSase-2 domain (Figure 4). We suspect that the wildtype allele (p.Tyr452 residue) is vital for activity of the CPSase-2 domain, and therefore should be under strong evolutionary constraint. To assess the selective constraint on $C A D$, we performed multi-species sequence alignment among 24 species using Clustal Omega software (Sievers et al., 2011). We found that this T-to-C transition mutation ( $C A D$ g.72399397T $>$ C) produces a tyrosine-to-cysteine substitution (p.Tyr452Cys) on CPSase-2 domain, replacing a fully conserved amino acid residue among the 24 species analyzed (Figure $4 \mathrm{~b}$ ) distributed in all life kingdoms.

\section{Large-Scale Genotyping Confirmed Recessive Inheritance of CAD p.Tyr452Cys in Normande Cattle}

We genotyped 33,323 Normande cattle for Chr11 g.72399397T >C (CAD p.Tyr452Cys) mutation (corresponding test in the chip: g.72399397A $>\mathrm{G}$ in the TOP format) using the Illumina EuroG10K BeadChip (Boichard et al., 2018; Table 4). In this data set, the NH7 haplotype and g.72399397G allele frequencies were 2.58 and $2.92 \%$, respectively (Table 5 ). We did not observe homozygotes for the g.72399397G allele, although 28 were expected under neutrality $\left(P<7 \times 10^{-13}\right)$, which largely corroborates the observed recessive-lethal inheritance of NH7 (Table 1). This CAD mutation was also strongly associated with NH7 haplotype status; the 
MESBAH-UDDIN ET AL.

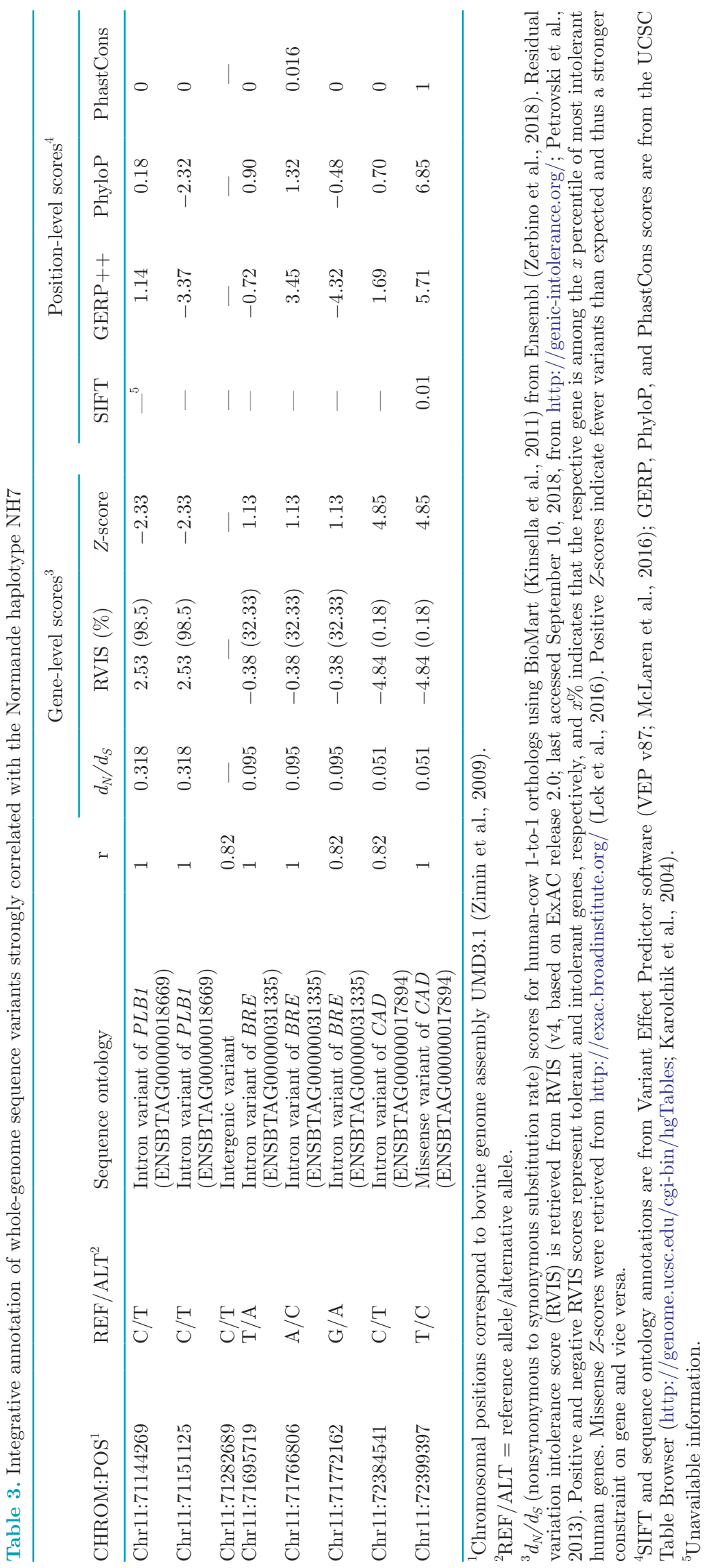


(a) CAD protein domains (ENSBTAP00000023783)

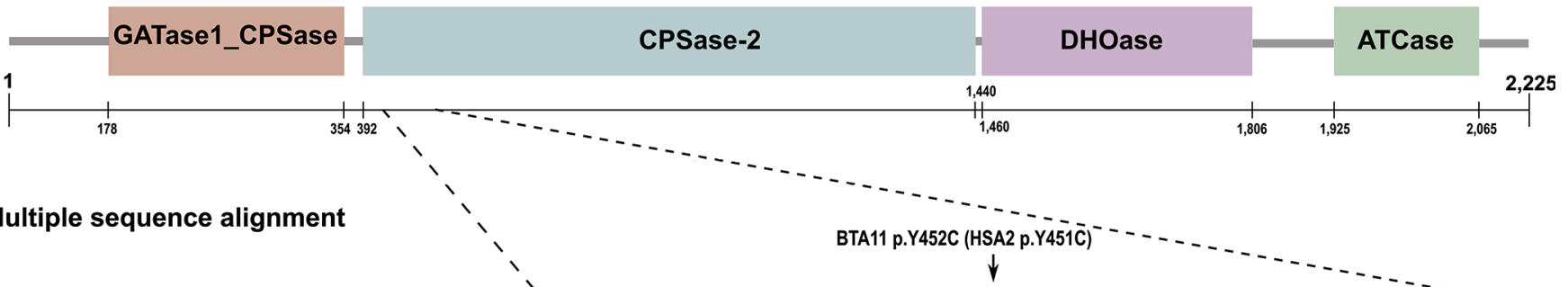

\begin{tabular}{|c|c|c|c|}
\hline \multirow{9}{*}{ 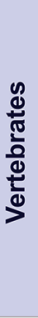 } & B. taurus & ENSBTAP00000023783 & 422-KALKEENIQTLIINPNIATVQTSQGLADKVYFLPITPHYVTQVIRNERPDGVLLTFGGQTA-482 \\
\hline & H. sapiens & ENSP00000264705 & 421-KALKEENIQTLLINPNIATVQTSQGLADKVYFLPITPHYVTQVIRNERPDGVLLTFGGQTA-481 \\
\hline & S. scrofa & ENSSSCP00000025052 & 421-KALKEENIQTLLINPNIATVQTSQGLADKVYFLPITPHYVTQVIRNERPDGVLLTFGGQTA-481 \\
\hline & C. I. familiaris & ENSCAFP00000007145 & 24-KALKEENIQTLIINPNIATVQTSQGLADKVYFLPITPHYVTQVIRNERPDGILLTFGGQTA-484 \\
\hline & L. africana & ENSLAFP00000010253 & 21-KALKEENIQTLLINPNIATVQTSQGLADKVYFLPITPHYVTQVIRNERPDGVLLTFGGQTA-481 \\
\hline & S. harrisii & ENSSHAP00000014754 & 6-KALKEENIQTLIINPNIATVQTSQGLADKVYFLPITPHYVTQVIRNERPDGVLLTFGGQTA-476 \\
\hline & M. musculus & ENSMUSP00000013773 & 21-KALKEENIQTLIINPNIATVQTSQGLADKVYFLPITLHYVTQVIRNERPDGVLLTFGGQTA-481 \\
\hline & G. gallus & ENSGALP00000026615 & 21-KALKEENIQTVLINPNIATVQTSKGLADKVYFLPITPEYVTQVIRNE \\
\hline & D. rerio & ENSDARP00000127377 & 23-KAMKEENIQTILINPNIATVQTSKGLADKVYFLPITPEYVTQVIKNE \\
\hline \multirow{5}{*}{ 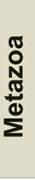 } & D. melanogaster & FBpp0309142 & 31-KAMRESNIQTVLINPNIATVQTSKGMADKCYFLPLTPHYVEQVIKSERPNGVLLTFGGQTA-491 \\
\hline & A. mellifera & GB54777-PA & 33-KALREECVQTLIINPNIATVQTSKGMADKVYFLPI IPEYVEQVIQSERPDGVLLTFGGQTA-493 \\
\hline & C. elegans & D2085.1 & 418-KALREEGIRTVLINPNIATVQTSKGFADFTYFLPITKEYVTDVIKKERPTGILCTFGGQTA-478 \\
\hline & C. gigas & EKC28536 & 23-KALKEEGIQTILINPNIATVQTSKGLADKVYFLPITTEYVTQVIKNERPDGVLLTFGGQTA-483 \\
\hline & D. magna & KZS18435 & 4-KALKEEGIHSILINPNIATVQTSKGMADKVYFLPITPHYVKQVIRQERPEGILLTFGGQTA-484 \\
\hline \multirow{2}{*}{$\begin{array}{l}\frac{\infty}{\tilde{N}} \\
\frac{\pi}{a}\end{array}$} & A. thaliana & $1 \mathrm{G} 29900.1$ & 6-KALREEGYEVILINSNPATIMTDPETANRTYIAPMTPELVEQVIEKERPDALLPTMGGQTA-186 \\
\hline & O. sativa (subsp. japonica) & B9EXM2 & ALAEEGYEVVLVNSNPATIMTDPDLAHRTYIGPMTPPLVERI IAAERPDALLPTMGGQTA-165 \\
\hline \multirow{3}{*}{ 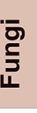 } & S. cerevisiae & YJL130C & 66-KALKEEGIYTILINPNIATIQTSKGLADKVYFVPVTAEFVRKVILHERPDAIYVTFGGQTA-526 \\
\hline & A. nidulans & CBF89223 & 508-KALKEEGIYTILINPNIATIQTSKGLADKVYFLPVNADFVRKVIKHERPDAIYVTFGGQTA-568 \\
\hline & S. pombe & SPBC215.08c.1 & 114-KALRESSVHTILINPNIATIQSSHSLADEIYFLPVTAEYLTHLIERENPDGILLTFGGQTA-174 \\
\hline \multirow{3}{*}{$\begin{array}{l}\frac{n}{0} \\
\frac{0}{\tilde{t}} \\
\frac{0}{0}\end{array}$} & P. infestans & PITG_10452 & LREEGVHVVLVNPNIATVQTSKGLADKVYFVPVRAETVLEIIKKI \\
\hline & P. falciparum (isolate 307) & CAD52216 & 704-KSLKECGIYVILVNPNIATVQTSKGLADKVYFLPVNCEFVEKI IKKEKPDFILCTFGGQTA-764 \\
\hline & D. discoideum & EAL69248 & 432-KALKEEGIKTILINPNIATVQTSPGLADKVYFLPVNASSVQKVIENENPDGILVTFGGQTA-492 \\
\hline \multirow{2}{*}{ 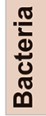 } & E. coli (K-12) & AAC73144 & 35-KALREEGYRVILVNSNPATIMTDPEMADATYIEPIHWEVVRKI IEKERPDAVLPTMGGQTA-095 \\
\hline & P. fluorescens (F113) & AEV60889 & 035-KALREEGYRVILVNSNPATIMTDPAMADATYIEPIKWQTVAKI IEKERPDALLPTMGGQTA-095 \\
\hline
\end{tabular}

Figure 4. Protein domains and conserved sequences in carbamoyl-phosphate synthetase 2, aspartate transcarbamylase, and dihydroorotase (CAD). (a) Schematic representation of bovine CAD protein domains from NCBI's Conserved Domain Database (CDD; domain architecture ID 11486011; https://www.ncbi.nlm.nih.gov/cdd). The diagram represents 4 functional protein domains: (1) a small subunit of the glutaminedependent form of carbamoyl-phosphate synthase II (GATase1_CPSase from 178 to 354; accession: cd01744); (2) a large subunit of carbamoylphosphate synthase II (CPSase-II from 392 to 1440; accession: TIGR01369) - which catalyzes the first step in de novo pyrimidine biosynthesis; (3) a subunit of dihydroorotase (DHOase from 1460 to 1806; accession: cd01316), which catalyzes the third step in de novo pyrimidine biosynthesis; and (4) a subunit of aspartate/ornithine carbamoyltransferase (ATCase_N from 1925 to 2065; accession: pfam02729), which catalyzes the second step in de novo pyrimidine biosynthesis. (b) Multi-species sequence alignment representing a 61-residue-long region in CPSase-II domain of $C A D$ protein (centering at BTA11 p.Y452C) among 9 vertebrates, 5 metazoans, 2 plants, 3 fungi, 3 protists, and 2 bacterial species. An arrow highlights the position of the $C A D$ mutation, in bovine and orthologous mutation in humans. An asterisk $(*)$ at the bottom of the alignment represents residues conserved in all 24 species (shaded vertical boxes); a colon (:) represents conservation among residues with strong similarity; a period (.) represents conservation among residues with weak similarity. HAS = Homo sapiens autosome.

Pearson correlation between g.72399397G allele dosages and haplotype status was $\mathrm{r}=0.94$.

However, the association was not perfect: 237 heterozygotes for the CAD mutation did not carry the NH7 haplotype and 8 heterozygous for NH7 did not carry the $C A D$ mutation (Table 5). Such imperfect association can arise from recombination between $\mathrm{NH} 7$ and other haplotypes, as well as for other reasons, such as genotyping, phasing, or imputation errors. Further investigations revealed that approximately $67 \%(158 / 237)$ of the heterozygotes for the $C A D$ mutation, but not for NH7, carried the same recombinant NH7 haplotype with a long stretch of source haplotype downstream. In addition, the 8 animals heterozygous for $C A D$ muta- 
Table 4. Genotypes at $C A D$ g.72399397A $>$ G mutation in 20 French cattle breeds ${ }^{1}$

\begin{tabular}{lrrc}
\hline & \multicolumn{3}{c}{ Genotype $^{2}$} \\
\cline { 2 - 4 } Breed & $A A$ & $A G$ & $G G$ \\
\hline Abondance & 5,161 & 0 & 0 \\
Aubrac & 66 & 0 & 0 \\
Blonde d'Aquitaine & 2,705 & 0 & 0 \\
Bretonne pie noir & 7 & 0 & 0 \\
Brown Swiss & 2,742 & 0 & 0 \\
Charolaise & 10,213 & 0 & 0 \\
Créole & 32 & 0 & 0 \\
Gasconne & 1 & 0 & 0 \\
Holstein & 180,565 & 0 & 0 \\
INRA95 & 20 & 0 & 0 \\
Jersey & 785 & 0 & 0 \\
Limousine & 887 & 0 & 0 \\
Montbéliarde & 138,851 & 0 & 0 \\
Normande & 31,376 & 1,947 & 0 \\
Parthenaise & 1,439 & 0 & 0 \\
Rouge des Prés & 4 & 0 & 0 \\
Salers & 15 & 0 & 0 \\
Simmental & 268 & 0 & 0 \\
Tarentaise & 2,750 & 0 & 0 \\
Vosgienne & 2,082 & 0 & 0 \\
\hline
\end{tabular}

${ }^{1}$ In total, 381,916 animals were genotyped for the candidate-SNP with EuroG10K (Illumina Inc., San Diego, CA) custom SNP chip (Boichard et al., 2018).

${ }^{2}$ Genotype $A A=C A D$ p. $452 \mathrm{Tyr} / \mathrm{Tyr} ; A G=C A D$ p. $452 \mathrm{Tyr} / \mathrm{Cys} ; G G$ $=C A D$ p. 452 Cys $/$ Cys.

tion didi not carry the original $\mathrm{NH} 7$ but a recombinant identical-by-state (IBS) portion of the haplotype.

Similarly, previous studies showed that haplotypes are not a perfect proxy for causal mutations (Michot et al., 2017; Fritz et al., 2018), and there are instances where 2 different versions of the same haplotype segregate in the population, one with and one without the causal mutation (Kipp et al., 2016; Menzi et al., 2016). Yet, haplotype is a good substitute to avoid carrier-tocarrier mating, when the causal mutation is unknown
Table 5. Concordance between Normande haplotype NH7 status and genotypes for $C A D$ g.72399397A $>\mathrm{G}$ in 33,323 Normande cattle

\begin{tabular}{lrrcr}
\hline Genotype & $+/+^{1}$ & $\mathrm{NH} 7 /+$ & $\mathrm{NH} 7 / \mathrm{NH} 7$ & Total \\
\hline g.72399397 $A A$ & 31,368 & 8 & 0 & 31,376 \\
g.72399397 $A G$ & 237 & 1,710 & 0 & 1,947 \\
g.72399397 $G G$ & 0 & 0 & 0 & 0 \\
Total & 31,605 & 1,718 & 0 & 33,323 \\
\hline
\end{tabular}

${ }^{1}$ Where + indicates the non-NH7 haplotype.

(VanRaden et al., 2011; Sahana et al., 2013) or when test results are confidential due to patents (Cole et al., 2016).

We next analyzed 348,593 additional animals (from 19 other French cattle breeds), genotyped for genomic selection, to elucidate whether this mutation is also observed in other populations. We found that the $C A D$ mutation was only segregating in Normande cattle (Table 4).

\section{Surviving CAD Homozygotes Exhibit Broad Range of Symptoms Depending on the Species and Nature of Mutation}

For verification, we genotyped Genetique, the cow homozygous for a $20-\mathrm{Mb}$ region including $\mathrm{NH}$, by PCR and Sanger sequencing and found that it was also homozygous for our candidate mutation (Figure 5).

Despite being alive and apparently healthy and fertile, this animal had very poor udder morphology (scored among the lowest 1\% of animals with same sire; Figure 1). This is consistent with previous observations in model organisms and humans, in which deleterious mutations in $C A D$ lead to embryonic lethality with incomplete penetrance (Norby, 1973; Falk and Nash, 1974; Willer et al., 2005; Franks et al., 2006; Cox et al., 2014; Ng et al., 2015). Of note, studies in humans and

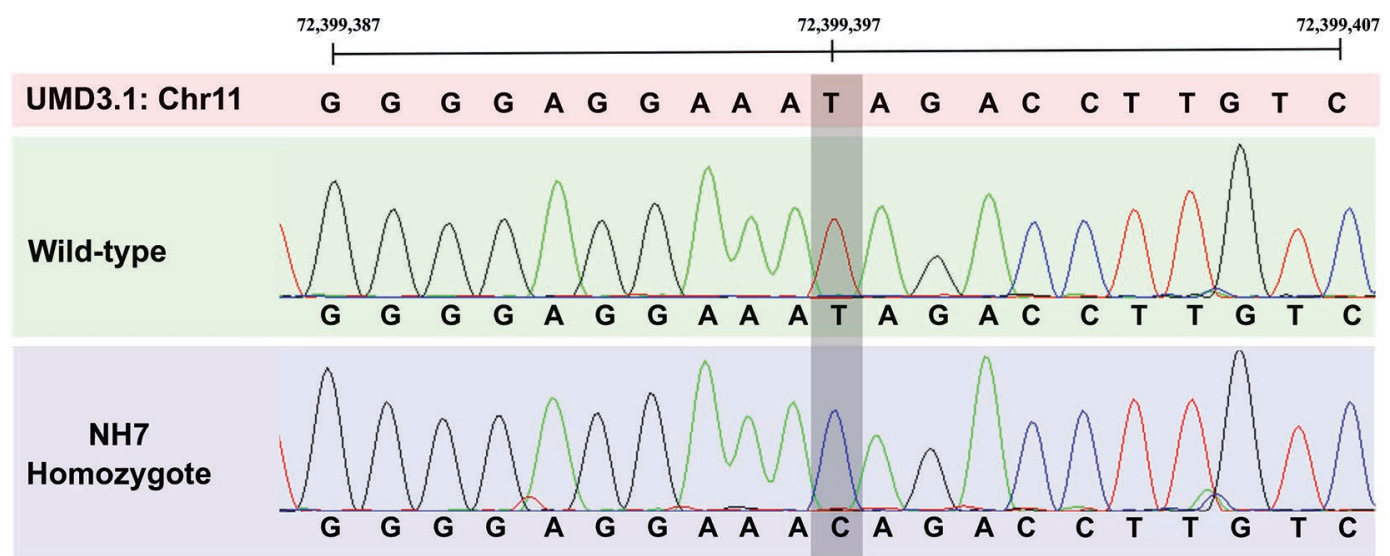

Figure 5. Genotype (UMD 3.1 assembly) of Normande haplotype NH7 homozygote at chromosome (Chr) $11 \mathrm{~g} .72399397 \mathrm{~T}>\mathrm{C}$ mutation. The $C A D$ mutation is indicated by the shaded vertical box. 

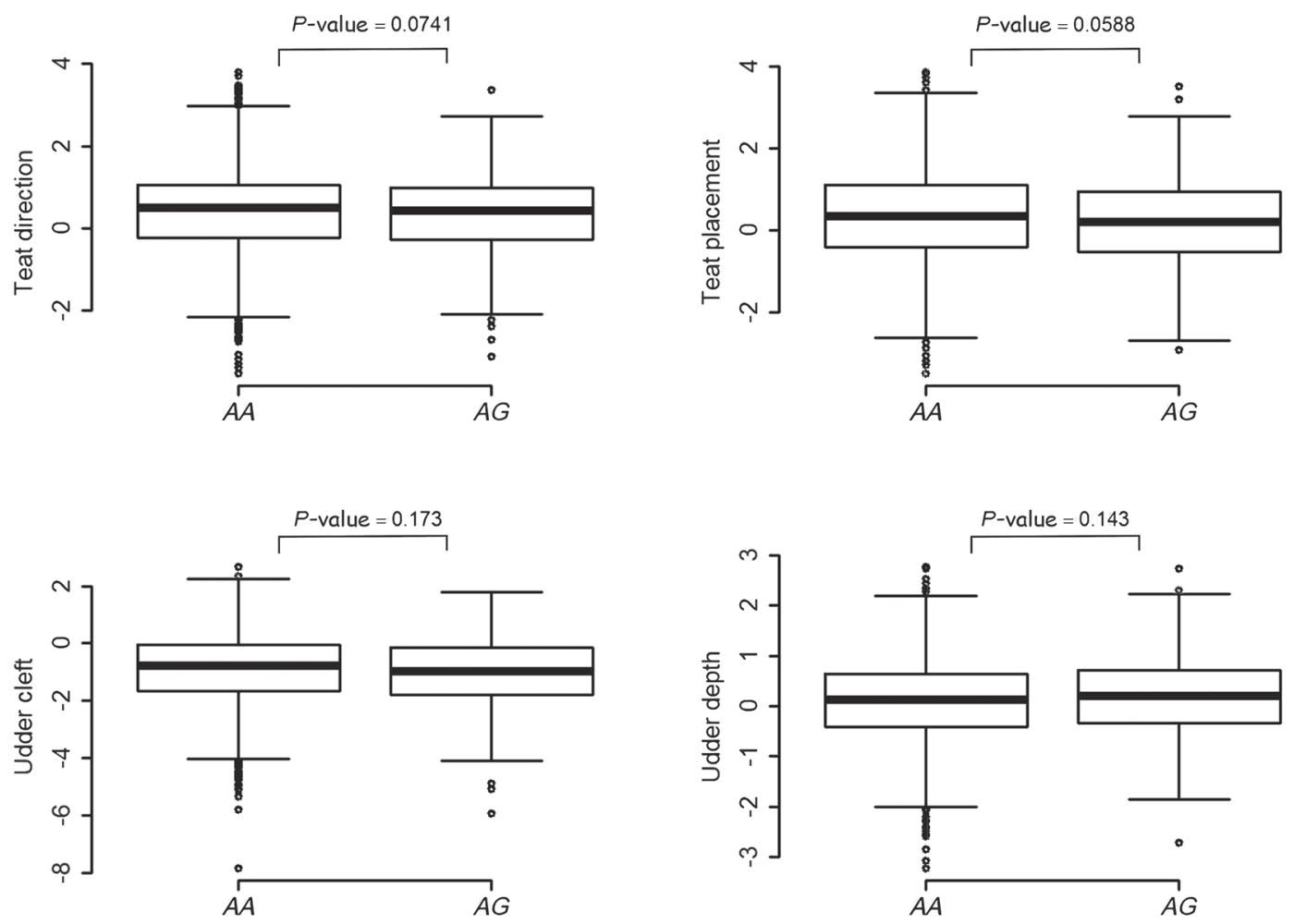

Figure 6. Effect of $C A D$ mutation on 4 udder traits. $P$-values are from Student's $t$-test on 250 animals with the $A G$ genotype (carriers) versus 2,912 animals with the $A A$ genotypes (noncarriers). The boxplots were drawn using R software's "boxplot" function (R Core Team, 2017). Here, the box represents the interquartile range (middle $50 \%$ of the data set); the solid line represents the median value; the lower and upper whiskers extend to 5th and 95th percentiles, respectively; and the circles represent data points outside the whisker range (outliers).

Drosophila demonstrated that uridine supplementation reduces the severity of the symptoms by the salvage pathway of pyrimidine biosynthesis (Falk and Nash, 1974; Ng et al., 2015; Koch et al., 2017). Depending on the species and nature of the mutation, surviving homozygotes display a broad range of clinical manifestations, including defective development of embryonic ectoderm and ectodermal derivatives. Defective pectoral fins in zebrafish (Willer et al., 2005), nerve cells in humans (Ng et al., 2015; Koch et al., 2017), and wings in fruit flies (Norby, 1970, 1973; Falk and Nash, 1974), are among such examples. The poor udder morphology observed in the homozygote cow could be added to this list because the mammary gland is also of ectodermal origin (Hens and Wysolmerski, 2005; Cowin and Wysolmerski, 2010; Macias and Hinck, 2012).

To test whether the $C A D$ mutation affected development of the mammary gland, we analyzed the performance of the daughters of 250 heterozygous carriers and 2,912 noncarriers for 4 traits (teat direction, teat placement, udder cleft, and udder depth). We did not find significant difference between daughter yield deviations of heterozygous and wild-type homozygous bulls (Figure 6). In addition, no udder-related QTL have been reported in Normande cattle, either within the
NH7 interval or on chromosome 11 (Boichard et al., 2003; Marete et al., 2018). This is in line with a possible recessive effect of the mutation on udder morphology in surviving homozygotes, although more live homozygous cows are needed to confirm this assumption.

\section{CONCLUSIONS}

Here, we performed a systematic screening for recessive lethal mutations from large-scale haplotype scan to single-variant resolution mapping in Normande cattle. We report the identification of a deleterious substitution in $C A D$ (p.Tyr452Cys) responsible for embryonic lethality with incomplete penetrance. We illustrate the influence of sample size, age of haplotype, and correction for multiple testing, on the discovery and replicability of HHD results. Furthermore, we highlight the importance of large-scale genotyping of candidate variants and phenotyping of homozygotes to validate or invalidate them. Although such approaches require collection of genomic data on hundreds of thousands of animals over several years, because of genomic selection this is now a routine practice in dairy cattle breeding. Finally, we added a test for $C A D$ (p.Tyr452Cys) to the EuroG10K BeadChip, which is routinely used for 
genomic evaluation in France. We recommend using $C A D$ information to avoid at-risk mating. Because the economic weight of embryonic lethal defects is limited, we also suggest including it in the breeding objective, as proposed by others, instead of eliminating all carriers.

\section{ACKNOWLEDGMENTS}

This study is part of the BOVANO project (ANR-14CE19-0011) funded by the French Agence Nationale de la Recherche (Paris, France) and APIS-GENE (Paris, France). Md Mesbah-Uddin benefited from a joint grant from the European Commission within the framework of the Erasmus-Mundus joint doctorate "EGS-ABG." Mesbah-Uddin's $\mathrm{PhD}$ project is also supported by the Center for Genomic Selection in Animals and Plants (GenSAP) funded by Innovation Fund Denmark (grant 0603-00519B). The authors are grateful to the partners of the 1000 Bull Genomes Consortium for their excellent collaboration. We are grateful to the Genotoul bioinformatics platform Toulouse Midi-Pyrenees (Bioinfo Genotoul) for providing computing and storage resources. MMU, DB, and $\mathrm{AC}$ conceived the study; MMU, CH, AB, PM, RL, MB, SF, DB, and AC contributed in collection or analysis of the data; MMU drafted the manuscript; GS, DB, and AC critically revised the manuscript; AC coordinated the study; and all authors read and approved the final manuscript.

\section{REFERENCES}

Adams, H. A., T. S. Sonstegard, P. M. VanRaden, D. J. Null, C. P. Van Tassell, D. M. Larkin, and H. A. Lewin. 2016. Identification of a nonsense mutation in APAF1 that is likely causal for a decrease in reproductive efficiency in Holstein dairy cattle. J. Dairy Sci. 99:6693-6701. https://doi.org/10.3168/jds.2015-10517.

Bjelland, D. W., K. A. Weigel, N. Vukasinovic, and J. D. Nkrumah. 2013. Evaluation of inbreeding depression in Holstein cattle using whole-genome SNP markers and alternative measures of genomic inbreeding. J. Dairy Sci. 96:4697-4706. https://doi.org/10.3168/ jds.2012-6435.

Boichard, D., M. Boussaha, A. Capitan, D. Rocha, C. Hozé, M. P. Sanchez, T. Tribout, R. Letaief, P. Croiseau, C. Grohs, W. Li, C. Harland, C. Charlier, M. S. Lund, G. Sahana, M. Georges, S. Barbier, W. Coppieters, S. Fritz, and B. Guldbrandtsen. 2018. Experience from large-scale use of the EuroGenomics custom SNP chip in cattle. Page 675 in Proc. World Congr. Genet. Appl. Livest. Prod., Auckland, New Zealand. AL Rae Centre for Genetics and Breeding, Massey University, Palmerston North, New Zealand. http:/ /www.wcgalp.org/system/files/proceedings/2018/experience-large -scale-use-eurogenomics-custom-snp-chip-cattle.pdf.

Boichard, D., H. Chung, R. Dassonneville, X. David, A. Eggen, S. Fritz, K. J. Gietzen, B. J. Hayes, C. T. Lawley, T. S. Sonstegard, C. P. Van Tassell, P. M. VanRaden, K. A. Viaud-Martinez, G. R. Wiggans, and L. D. C. Bovine. 2012a. Design of a bovine lowdensity SNP array optimized for imputation. PLoS One 7:e34130. https://doi.org/10.1371/journal.pone.0034130.

Boichard, D., C. Grohs, F. Bourgeois, F. Cerqueira, R. Faugeras, A. Neau, R. Rupp, Y. Amigues, M. Y. Boscher, and H. Leveziel. 2003. Detection of genes influencing economic traits in three French dairy cattle breeds. Genet. Sel. Evol. 35:77-101. https://doi.org/ 10.1051/gse:2002037.

Boichard, D., C. Grohs, P. Michot, C. Danchin-Burge, A. Capitan, L. Genestout, S. Barbier, and S. Fritz. 2016. Prise en compte des anomalies génétiques en sélection: Le cas des bovins. INRA Prod. Anim. 29:351-358.

Boichard, D., F. Guillaume, A. Baur, P. Croiseau, M. N. Rossignol, M. Y. Boscher, T. Druet, L. Genestout, J. J. Colleau, L. Journaux, V Ducrocq, and S. Fritz. 2012b. Genomic selection in French dairy cattle. Anim. Prod. Sci. 52:115-120. https://doi.org/10.1071/ AN11119.

Casper, J., A. S. Zweig, C. Villarreal, C. Tyner, M. L. Speir, K. R Rosenbloom, B. J. Raney, C. M. Lee, B. T. Lee, D. Karolchik, A S. Hinrichs, M. Haeussler, L. Guruvadoo, J. Navarro Gonzalez, D. Gibson, I. T. Fiddes, C. Eisenhart, M. Diekhans, H. Clawson, G. P. Barber, J. Armstrong, D. Haussler, R. M. Kuhn, and W. J. Kent. 2018. The UCSC Genome Browser database: 2018 update. Nucleic Acids Res. 46:D762-D769. https://doi.org/10.1093/nar/ gkx1020.

Charlier, C., W. Coppieters, F. Rollin, D. Desmecht, J. S. Agerholm, N. Cambisano, E. Carta, S. Dardano, M. Dive, C. Fasquelle, J. C. Frennet, R. Hanset, X. Hubin, C. Jorgensen, L. Karim, M. Kent, K. Harvey, B. R. Pearce, P. Simon, N. Tama, H. Nie, S. Vandeputte, S. Lien, M. Longeri, M. Fredholm, R. J. Harvey, and M. Georges. 2008. Highly effective SNP-based association mapping and management of recessive defects in livestock. Nat. Genet. 40:449-454. https://doi.org/10.1038/ng.96.

Chen, K., J. W. Wallis, M. D. McLellan, D. E. Larson, J. M. Kalicki, C. S. Pohl, S. D. McGrath, M. C. Wendl, Q. Zhang, D. P. Locke, X. Shi, R. S. Fulton, T. J. Ley, R. K. Wilson, L. Ding, and E. R. Mardis. 2009. BreakDancer: an algorithm for high-resolution mapping of genomic structural variation. Nat. Methods 6:677-681. https://doi.org/10.1038/nmeth.1363.

Cole, J. B., D. J. Null, and P. M. VanRaden. 2016. Phenotypic and genetic effects of recessive haplotypes on yield, longevity, and fertility. J. Dairy Sci. 99:7274-7288. https://doi.org/10.3168/jds.2015 $-10777$.

Cowin, P., and J. Wysolmerski. 2010. Molecular mechanisms guiding embryonic mammary gland development. Cold Spring Harb. Perspect. Biol. 2:a003251. https://doi.org/10.1101/cshperspect .a003251.

Cox, J. A., A. LaMora, S. L. Johnson, and M. M. Voigt. 2014. Novel role for carbamoyl phosphate synthetase 2 in cranial sensory circuit formation. Int. J. Dev. Neurosci. 33:41-48. https://doi.org/10 .1016/j.ijdevneu.2013.11.003.

Daetwyler, H. D., A. Capitan, H. Pausch, P. Stothard, R. van Binsbergen, R. F. Brondum, X. Liao, A. Djari, S. C. Rodriguez, C. Grohs, D. Esquerre, O. Bouchez, M. N. Rossignol, C. Klopp, D. Rocha, S. Fritz, A. Eggen, P. J. Bowman, D. Coote, A. J. Chamberlain, C. Anderson, C. P. VanTassell, I. Hulsegge, M. E. Goddard, B. Guldbrandtsen, M. S. Lund, R. F. Veerkamp, D. A. Boichard, R. Fries, and B. J. Hayes. 2014. Whole-genome sequencing of 234 bulls facilitates mapping of monogenic and complex traits in cattle. Nat. Genet. 46:858-865. https://doi.org/10.1038/ng.3034.

Davydov, E. V., D. L. Goode, M. Sirota, G. M. Cooper, A. Sidow, and S. Batzoglou. 2010. Identifying a high fraction of the human genome to be under selective constraint using GERP ++ . PLOS Comput. Biol. 6:e1001025. https://doi.org/10.1371/journal.pcbi .1001025 .

Fairbanks, L. D., M. Bofill, K. Ruckemann, and H. A. Simmonds. 1995. Importance of ribonucleotide availability to proliferating Tlymphocytes from healthy humans. Disproportionate expansion of pyrimidine pools and contrasting effects of de novo synthesis inhibitors. J. Biol. Chem. 270:29682-29689.

Falk, D. R., and D. Nash. 1974. Sex-linked auxotrophic and putative auxotrophic mutants of Drosophila melanogaster. Genetics 76:755-766.

Franks, D. M., T. Izumikawa, H. Kitagawa, K. Sugahara, and P. G. Okkema. 2006. C. elegans pharyngeal morphogenesis requires both de novo synthesis of pyrimidines and synthesis of heparan sulfate 
proteoglycans. Dev. Biol. 296:409-420. https://doi.org/10.1016/j ydbio.2006.06.008.

Fritz, S., A. Capitan, A. Djari, S. C. Rodriguez, A. Barbat, A. Baur, C. Grohs, B. Weiss, M. Boussaha, D. Esquerre, C. Klopp, D. Rocha, and D. Boichard. 2013. Detection of haplotypes associated with prenatal death in dairy cattle and identification of deleterious mutations in GART, SHBG and SLC37A2. PLoS One 8:e65550. https://doi.org/10.1371/journal.pone.0065550.

Fritz, S., C. Hoze, E. Rebours, A. Barbat, M. Bizard, A. Chamberlain, C. Escouflaire, C. Vander Jagt, M. Boussaha, C. Grohs, A. Allais-Bonnet, M. Philippe, A. Vallee, Y. Amigues, B. J. Hayes, D. Boichard, and A. Capitan. 2018. An initiator codon mutation in SDE2 causes recessive embryonic lethality in Holstein cattle. J. Dairy Sci. https://doi.org/10.3168/jds.2017-14119.

Hens, J. R., and J. J. Wysolmerski. 2005. Key stages of mammary gland development: molecular mechanisms involved in the formation of the embryonic mammary gland. Breast Cancer Res. 7:220224. https://doi.org/10.1186/bcr1306.

ICAR. 2018. Guidelines for conformation recording of dairy cattle, beef cattle and dairy goats. Accessed Oct. 25, 2018. https://www .icar.org/Guidelines/05-Conformation-Recording.pdf.

IDELE. 2017. Indicators of genetic variability - Normande. Accessed Oct. 25, 2018. http://idele.fr/fileadmin/medias/Documents/SIG 56_2017.pdf.

Jones, M. E. 1980. Pyrimidine nucleotide biosynthesis in animals: Genes, enzymes, and regulation of UMP biosynthesis. Annu. Rev. Biochem. 49:253-279. https://doi.org/10.1146/annurev.bi.49 .070180 .001345 .

Karolchik, D., A. S. Hinrichs, T. S. Furey, K. M. Roskin, C. W. Sugnet, D. Haussler, and W. J. Kent. 2004. The UCSC Table Browser data retrieval tool. Nucleic Acids Res. 32:D493-D496. https://doi .org/10.1093/nar/gkh103.

Kersey, P. J., J. E. Allen, A. Allot, M. Barba, S. Boddu, B. J. Bolt, D. Carvalho-Silva, M. Christensen, P. Davis, C. Grabmueller, N. Kumar, Z. Liu, T. Maurel, B. Moore, M. D. McDowall, U. Maheswari, G. Naamati, V. Newman, C. K. Ong, M. Paulini, H. Pedro, E. Perry, M. Russell, H. Sparrow, E. Tapanari, K. Taylor, A. Vullo, G. Williams, A. Zadissia, A. Olson, J. Stein, S. Wei, M. Tello-Ruiz, D. Ware, A. Luciani, S. Potter, R. D. Finn, M. Urban, K. E. Hammond-Kosack, D. M. Bolser, N. De Silva, K. L. Howe, N. Langridge, G. Maslen, D. M. Staines, and A. Yates. 2018. Ensembl Genomes 2018: An integrated omics infrastructure for nonvertebrate species. Nucleic Acids Res. 46:D802-D808. https://doi .org/10.1093/nar/gkx1011.

Kinsella, R. J., A. Kahari, S. Haider, J. Zamora, G. Proctor, G. Spudich, J. Almeida-King, D. Staines, P. Derwent, A. Kerhornou, P. Kersey, and P. Flicek. 2011. Ensembl BioMarts: A hub for data retrieval across taxonomic space. Database (Oxford) 2011:bar030. https://doi.org/10.1093/database/bar030.

Kipp, S., D. Segelke, S. Schierenbeck, F. Reinhardt, R. Reents, C. Wurmser, H. Pausch, R. Fries, G. Thaller, J. Tetens, J. Pott, D. Haas, B. B. Raddatz, M. Hewicker-Trautwein, I. Proios, M. Schmicke, and W. Grunberg. 2016. Identification of a haplotype associated with cholesterol deficiency and increased juvenile mortality in Holstein cattle. J. Dairy Sci. 99:8915-8931. https://doi .org/10.3168/jds.2016-11118.

Koch, J., J. A. Mayr, B. Alhaddad, C. Rauscher, J. Bierau, R. Kovacs-Nagy, K. L. Coene, I. Bader, M. Holzhacker, H. Prokisch, H. Venselaar, R. A. Wevers, F. Distelmaier, T. Polster, S. Leiz, C. Betzler, T. M. Strom, W. Sperl, T. Meitinger, S. B. Wortmann, and T. B. Haack. 2017. CAD mutations and uridine-responsive epileptic encephalopathy. Brain 140:279-286. https://doi.org/10 .1093/brain/aww300

Kumar, P., S. Henikoff, and P. C. Ng. 2009. Predicting the effects of coding non-synonymous variants on protein function using the SIFT algorithm. Nat. Protoc. 4:1073-1081. https://doi.org/10 $.1038 /$ nprot.2009.86.

Lek, M., K. J. Karczewski, E. V. Minikel, K. E. Samocha, E. Banks, T. Fennell, A. H. O'Donnell-Luria, J. S. Ware, A. J. Hill, B. B. Cummings, T. Tukiainen, D. P. Birnbaum, J. A. Kosmicki, L. E. Duncan, K. Estrada, F. Zhao, J. Zou, E. Pierce-Hoffman, J. Berg- hout, D. N. Cooper, N. Deflaux, M. DePristo, R. Do, J. Flannick, M. Fromer, L. Gauthier, J. Goldstein, N. Gupta, D. Howrigan, A. Kiezun, M. I. Kurki, A. L. Moonshine, P. Natarajan, L. Orozco, G. M. Peloso, R. Poplin, M. A. Rivas, V. Ruano-Rubio, S. A. Rose, D. M. Ruderfer, K. Shakir, P. D. Stenson, C. Stevens, B. P. Thomas, G. Tiao, M. T. Tusie-Luna, B. Weisburd, H. H. Won, D. Yu, D. M. Altshuler, D. Ardissino, M. Boehnke, J. Danesh, S. Donnelly, R. Elosua, J. C. Florez, S. B. Gabriel, G. Getz, S. J. Glatt, C. M. Hultman, S. Kathiresan, M. Laakso, S. McCarroll, M. I. McCarthy, D. McGovern, R. McPherson, B. M. Neale, A. Palotie, S. M. Purcell, D. Saleheen, J. M. Scharf, P. Sklar, P. F. Sullivan, J. Tuomilehto, M. T. Tsuang, H. C. Watkins, J. G. Wilson, M. J. Daly, D. G. MacArthur, and C. Exome Aggregation. 2016. Analysis of protein-coding genetic variation in 60,706 humans. Nature 536:285-291. https://doi.org/10.1038/nature19057.

Letaief, R., E. Rebours, C. Grohs, C. Meersseman, S. Fritz, L. Trouilh, D. Esquerre, J. Barbieri, C. Klopp, R. Philippe, V. Blanquet, D. Boichard, D. Rocha, and M. Boussaha. 2017. Identification of copy number variation in French dairy and beef breeds using nextgeneration sequencing. Genet. Sel. Evol. 49:77. https://doi.org/10 $.1186 / \mathrm{s} 12711-017-0352-\mathrm{z}$.

Macias, H., and L. Hinck. 2012. Mammary gland development. Wiley Interdiscip. Rev. Dev. Biol. 1:533-557. https://doi.org/10.1002/ wdev.35.

Marchler-Bauer, A., Y. Bo, L. Han, J. He, C. J. Lanczycki, S. Lu, F. Chitsaz, M. K. Derbyshire, R. C. Geer, N. R. Gonzales, M. Gwadz, D. I. Hurwitz, F. Lu, G. H. Marchler, J. S. Song, N. Thanki, Z. Wang, R. A. Yamashita, D. Zhang, C. Zheng, L. Y. Geer, and S. H. Bryant. 2017. CDD/SPARCLE: Functional classification of proteins via subfamily domain architectures. Nucleic Acids Res. 45:D200-D203. https://doi.org/10.1093/nar/gkw1129.

Marete, A., M. S. Lund, D. Boichard, and Y. Ramayo-Caldas. 2018. A system-based analysis of the genetic determinism of udder conformation and health phenotypes across three French dairy cattle breeds. PLoS One 13:e0199931. https://doi.org/10.1371/journal .pone.0199931.

Matukumalli, L. K., C. T. Lawley, R. D. Schnabel, J. F. Taylor, M. F. Allan, M. P. Heaton, J. O'Connell, S. S. Moore, T. P. Smith, T. S. Sonstegard, and C. P. Van Tassell. 2009. Development and characterization of a high density SNP genotyping assay for cattle. PLoS One 4:e5350. https://doi.org/10.1371/journal.pone.0005350.

McClure, M. C., D. Bickhart, D. Null, P. Vanraden, L. Xu, G. Wiggans, G. Liu, S. Schroeder, J. Glasscock, J. Armstrong, J. B. Cole, C. P. Van Tassell, and T. S. Sonstegard. 2014. Bovine exome sequence analysis and targeted SNP genotyping of recessive fertility defects $\mathrm{BH} 1, \mathrm{HH} 2$, and $\mathrm{HH} 3$ reveal a putative causative mutation in SMC2 for HH3. PLoS One 9:e92769. https://doi.org/10.1371/ journal.pone.0092769.

McLaren, W., L. Gil, S. E. Hunt, H. S. Riat, G. R. Ritchie, A. Thormann, P. Flicek, and F. Cunningham. 2016. The Ensembl Variant Effect Predictor. Genome Biol. 17:122. https://doi.org/10.1186/ s13059-016-0974-4.

Menzi, F., N. Besuchet-Schmutz, M. Fragniere, S. Hofstetter, V. Jagannathan, T. Mock, A. Raemy, E. Studer, K. Mehinagic, N. Regenscheit, M. Meylan, F. Schmitz-Hsu, and C. Drogemuller. 2016. A transposable element insertion in APOB causes cholesterol deficiency in Holstein cattle. Anim. Genet. 47:253-257. https://doi .org/10.1111/age.12410.

Michot, P., S. Fritz, A. Barbat, M. Boussaha, M. C. Deloche, C. Grohs, C. Hoze, L. Le Berre, D. Le Bourhis, O. Desnoes, P. Salvetti, L. Schibler, D. Boichard, and A. Capitan. 2017. A missense mutation in PFAS (phosphoribosylformylglycinamidine synthase) is likely causal for embryonic lethality associated with the MH1 haplotype in Montbéliarde dairy cattle. J. Dairy Sci. 100:8176-8187. https:/ /doi.org/10.3168/jds.2017-12579.

Mitchell, A. D., and N. J. Hoogenraad. 1975. De novo pyrimidine nucleotide biosynthesis in synchronized rat hepatoma (HTC) cells and mouse embryo fibroblast (3T3) cells. Exp. Cell Res. 93:105110.

Moreno-Morcillo, M., A. Grande-Garcia, A. Ruiz-Ramos, F. Del CanoOchoa, J. Boskovic, and S. Ramon-Maiques. 2017. Structural in- 
sight into the core of $\mathrm{CAD}$, the multifunctional protein leading de novo pyrimidine biosynthesis. Structure 25:912-923.E5. https://doi .org/10.1016/j.str.2017.04.012.

Ng, B. G., L. A. Wolfe, M. Ichikawa, T. Markello, M. He, C. J. Tifft, W. A. Gahl, and H. H. Freeze. 2015. Biallelic mutations in CAD, impair de novo pyrimidine biosynthesis and decrease glycosylation precursors. Hum. Mol. Genet. 24:3050-3057. https://doi.org/10 $.1093 / \mathrm{hmg} / \mathrm{ddv} 057$.

Norby, S. 1970. A specific nutritional requirement for pyrimidines in rudimentary mutants of Drosophila melanogaster. Hereditas $66: 205-214$.

Norby, S. 1973. The biochemical genetics of rudimentary mutants of Drosophila melanogaster. I. Aspartate carbamoyltransferase levels in complementing and non-complementing strains. Hereditas $73: 11-16$.

Pausch, H., H. Schwarzenbacher, J. Burgstaller, K. Flisikowski, C. Wurmser, S. Jansen, S. Jung, A. Schnieke, T. Wittek, and R. Fries. 2015. Homozygous haplotype deficiency reveals deleterious mutations compromising reproductive and rearing success in cattle. BMC Genomics 16:312. https://doi.org/10.1186/s12864-015-1483 -7 .

Petrovski, S., Q. Wang, E. L. Heinzen, A. S. Allen, and D. B. Goldstein. 2013. Genic intolerance to functional variation and the in terpretation of personal genomes. PLoS Genet. 9:e1003709. https: //doi.org/10.1371/journal.pgen.1003709.

Pollard, K. S., M. J. Hubisz, K. R. Rosenbloom, and A. Siepel. 2010. Detection of nonneutral substitution rates on mammalian phylogenies. Genome Res. 20:110-121. https://doi.org/10.1101/gr .097857 .109

R Core Team. 2017. R: A language and environment for statistical computing. R Foundation for Statistical Computing, Vienna, Austria.

Rausch, T., T. Zichner, A. Schlattl, A. M. Stutz, V. Benes, and J. O. Korbel. 2012. DELLY: Structural variant discovery by integrated paired-end and split-read analysis. Bioinformatics 28:i333-i339. https://doi.org/10.1093/bioinformatics/bts378.

Reece, W. O., H. H. Erickson, J. P. Goff, and E. E. Uemura. 2015. Dukes' Physiology of Domestic Animals. 13th ed. Wiley Blackwell, Ames, IA.

Sahana, G., U. S. Nielsen, G. P. Aamand, M. S. Lund, and B. Guldbrandtsen. 2013. Novel harmful recessive haplotypes identified for fertility traits in Nordic Holstein cattle. PLoS One 8:e82909. https: //doi.org/10.1371/journal.pone.0082909.

Sargolzaei, M., J. P. Chesnais, and F. S. Schenkel. 2014. A new approach for efficient genotype imputation using information from relatives. BMC Genomics 15:478. https://doi.org/10.1186/1471 $-2164-15-478$.

Schwarzenbacher, H., J. Burgstaller, F. R. Seefried, C. Wurmser, M. Hilbe, S. Jung, C. Fuerst, N. Dinhopl, H. Weissenbock, B. FuerstWaltl, M. Dolezal, R. Winkler, O. Grueter, U. Bleul, T. Wittek, R. Fries, and H. Pausch. 2016a. A missense mutation in TUBD1 is associated with high juvenile mortality in Braunvieh and Fleckvieh cattle. BMC Genomics 17:400. https://doi.org/10.1186/s12864 $-016-2742-y$.

Schwarzenbacher, H., C. Wurmser, K. Flisikowski, L. Misurova, S. Jung, M. C. Langenmayer, A. Schnieke, G. Knubben-Schweizer, R. Fries, and H. Pausch. 2016b. A frameshift mutation in GON4L is associated with proportionate dwarfism in Fleckvieh cattle. Genet. Sel. Evol. 48:25. https://doi.org/10.1186/s12711-016-0207-z.
Segelke, D., H. Taubert, F. Reinhardt, and G. Thaller. 2016. Considering genetic characteristics in German Holstein breeding programs. J. Dairy Sci. 99:458-467. https://doi.org/10.3168/jds.2015-9764.

Sievers, F., A. Wilm, D. Dineen, T. J. Gibson, K. Karplus, W. Li, R. Lopez, H. McWilliam, M. Remmert, J. Soding, J. D. Thompson, and D. G. Higgins. 2011. Fast, scalable generation of high-quality protein multiple sequence alignments using Clustal Omega. Mol. Syst. Biol. 7:539. https://doi.org/10.1038/msb.2011.75

Sonstegard, T. S., J. B. Cole, P. M. VanRaden, C. P. Van Tassell, D. J. Null, S. G. Schroeder, D. Bickhart, and M. C. McClure 2013. Identification of a nonsense mutation in CWC15 associated with decreased reproductive efficiency in Jersey cattle. PLoS One 8:e54872. https://doi.org/10.1371/journal.pone.0054872.

UniProt. 2017. UniProt: The universal protein knowledgebase. Nucleic Acids Res. 45:D158-D169. https://doi.org/10.1093/nar/gkw1099.

Untergasser, A., I. Cutcutache, T. Koressaar, J. Ye, B. C. Faircloth M. Remm, and S. G. Rozen. 2012. Primer3-new capabilities and interfaces. Nucleic Acids Res. 40:e115. https://doi.org/10.1093/ nar/gks596.

VanRaden, P. M., K. M. Olson, D. J. Null, and J. L. Hutchison. 2011. Harmful recessive effects on fertility detected by absence of homozygous haplotypes. J. Dairy Sci. 94:6153-6161. https://doi.org/10 $.3168 /$ jds.2011-4624.

Weckx, S., J. Del-Favero, R. Rademakers, L. Claes, M. Cruts, P. De Jonghe, C. Van Broeckhoven, and P. De Rijk. 2005. novoSNP, a novel computational tool for sequence variation discovery. Genome Res. 15:436-442. https://doi.org/10.1101/gr.2754005.

Weigel, K. A. 2001. Controlling inbreeding in modern breeding programs. J. Dairy Sci. 84:E177-E184. https://doi.org/10.3168/jds .S0022-0302(01)70213-5.

Willer, G. B., V. M. Lee, R. G. Gregg, and B. A. Link. 2005. Analysis of the Zebrafish perplexed mutation reveals tissue-specific roles for de novo pyrimidine synthesis during development. Genetics 170:1827-1837. https://doi.org/10.1534/genetics.105.041608.

Ye, K., M. H. Schulz, Q. Long, R. Apweiler, and Z. Ning. 2009. Pindel: A pattern growth approach to detect break points of large deletions and medium sized insertions from paired-end short reads. Bioinformatics 25:2865-2871. https://doi.org/10.1093/ bioinformatics/btp394.

Zerbino, D. R., P. Achuthan, W. Akanni, M. R. Amode, D. Barrell, J. Bhai, K. Billis, C. Cummins, A. Gall, C. G. Giron, L. Gil, L. Gordon, L. Haggerty, E. Haskell, T. Hourlier, O. G. Izuogu, S. H. Janacek, T. Juettemann, J. K. To, M. R. Laird, I. Lavidas, Z. Liu, J. E. Loveland, T. Maurel, W. McLaren, B. Moore, J. Mudge, D. N. Murphy, V. Newman, M. Nuhn, D. Ogeh, C. K. Ong, A. Parker, M. Patricio, H. S. Riat, H. Schuilenburg, D. Sheppard, H. Sparrow, K. Taylor, A. Thormann, A. Vullo, B. Walts, A. Zadissa, A. Frankish, S. E. Hunt, M. Kostadima, N. Langridge, F. J. Martin, M. Muffato, E. Perry, M. Ruffier, D. M. Staines, S. J. Trevanion, B. L. Aken, F. Cunningham, A. Yates, and P. Flicek. 2018. Ensembl 2018. Nucleic Acids Res. 46:D754-D761. https://doi.org/10 $.1093 /$ nar/gkx1098.

Zimin, A. V., A. L. Delcher, L. Florea, D. R. Kelley, M. C. Schatz, D. Puiu, F. Hanrahan, G. Pertea, C. P. Van Tassell, T. S. Sonstegard, G. Marcais, M. Roberts, P. Subramanian, J. A. Yorke, and S. L. Salzberg. 2009. A whole-genome assembly of the domestic cow, Bos taurus. Genome Biol. 10:R42. https://doi.org/10.1186/ gb-2009-10-4-r42 